\title{
Peripheral Myeloid Cell EP2 Activation Contributes to the Deleterious Consequences of Status Epilepticus
}

\author{
Nicholas H. Varvel, Claudia Espinosa-Garcia, Sarah Hunter-Chang, Di Chen, Ariel Biegel, Allison Hsieh, \\ Lisa Blackmer-Raynolds, Thota Ganesh, and ${ }^{\circledR}$ Raymond Dingledine \\ Department of Pharmacology and Chemical Biology, Emory University School of Medicine, Atlanta, Georgia 30322
}

A multidimensional inflammatory response ensues after status epilepticus (SE), driven partly by cyclooxygenase-2-mediated activation of prostaglandin EP2 receptors. The inflammatory response is typified by astrocytosis, microgliosis, erosion of the blood-brain barrier (BBB), formation of inflammatory cytokines, and brain infiltration of blood-borne monocytes. Our previous studies have shown that inhibition of monocyte brain invasion or systemic administration of an EP2 receptor antagonist relieves multiple deleterious consequences of SE. Here we identify those effects of EP2 antagonism that are reproduced by conditional ablation of EP2 receptors in immune myeloid cells and show that systemic EP2 antagonism blocks monocyte brain entry in male mice. The induction of hippocampal IL-6 after pilocarpine SE was nearly abolished in EP2 conditional KO mice. Serum albumin levels in the cortex, a measure of BBB breakdown, were significantly higher after SE in EP2-sufficient mice but not in EP2 conditional KOs. EP2 deficiency in innate immune cells accelerated the recovery from sickness behaviors following SE. Surprisingly, neurodegeneration was not alleviated in myeloid conditional KOs. Systemic EP2 antagonism prevented monocyte brain infiltration and provided broader rescue of SE-induced effects than myeloid EP2 ablation, including neuroprotection and broader suppression of inflammatory mediators. Reporter expression indicated that the cellular target of CD11b-driven Cre was circulating myeloid cells but, unexpectedly, not microglia. These findings indicate that activation of EP2 receptors on immune myeloid cells drives substantial deficits in behavior and disrupts the BBB after SE. The benefits of systemic EP2 antagonism can be attributed, in part, to blocking brain recruitment of blood-borne monocytes.

Key words: Cox-2; EP2; epilepsy; inflammation; monocytes; status epilepticus

Significance Statement

Unabated seizures reduce quality of life, promote the development of epilepsy, and can be fatal. We previously identified activation of prostaglandin EP2 receptors as a driver of undesirable consequences of seizures. However, the relevant EP2-expressing cell types remain unclear. Here we identify peripheral innate immune cells as a driver of the EP2-related negative consequences of seizures. Removal of EP2 from peripheral immune cells was beneficial, abolishing production of a key inflammatory cytokine, accelerating weight regain, and limiting behavioral deficits. These findings provide evidence that EP2 engagement on peripheral immune and brain endothelia contributes to the deleterious effects of SE, and will assist in the development of beneficial therapies to enhance quality of life in individuals who suffer prolonged seizures.

Received Aug. 4, 2020; revised Nov. 6, 2020; accepted Nov. 23, 2020

Author contributions: N.H.V., T.G., and R.D. designed research; N.H.V. and L.B.-R. performed research; N.H.V., C.E.-G., S.H.-C., D.C., A.B., A.H., L.B.-R., and R.D. analyzed data; N.H.V. wrote the first draft of the paper; N.H.V., T.G., and R.D. edited the paper; N.H.V. wrote the paper.

The authors declare no competing financial interests.

This work was supported in part by Emory University Pediatric/Winship Flow Cytometry Core, Emory University Genomics Core, and National Institutes of Health, Office of the Director, National Institute of Neurological Disorders and Stroke Grants R01 NS097776 and R01 NS112308 to R.D., R01 NS112350 to N.H.V., R21 NS101167 to T.G., and National institute of Aging Grant U01 AG052460 to T.G. This work was supported in part by the Emory University Integrated Cellular Imaging Microscopy Core of the Emory Neuroscience, National Institute of Neurological Disorders and Stroke Core Facilities Grant 5P30NS055077. The content is solely the responsibility of the authors and does not necessarily reflect the official views of the National Institutes of Health. We thank K. Andreasson (Stanford University) for sharing EP2 flox mice and CD11b-Cre mice; Tomohiro Aoki (National Cerebral and Cardiovascular Center, Suita, Osaka, Japan) and Richard Breyer (Vanderbilt University) for EP2 global K0 tissues; M. Tansey (Emory University) for use of stereology equipment; and A. Rea (Emory University) for assistance with flow sorting.

Correspondence should be addressed to Nicholas H. Varvel at nvarvel@emory.edu.

https://doi.org/10.1523/JNEUROSCI.2040-20.2020

Copyright $\odot 2021$ the authors

\section{Introduction}

In both human and rodents, the extended seizures of status epilepticus (SE) can result in marked brain inflammation, temporary opening of the blood-brain barrier (BBB), and neuronal damage in select brain regions leading to substantial decline in quality of life. Patients in refractory SE typically show elevated CSF levels of chemokines and cytokines, such as IL-6, IL-8, and CXCL10 (Sakuma et al., 2015). Examination of the temporal cortex in a patient with newonset focal seizures that progressed into refractory SE revealed robust activation of astrocytes and microglia (van Vliet et al., 2007). Moreover, brain-invading monocytes have been observed in hippocampal tissue of epilepsy patients (Broekaart et al., 2018).

In rodent hippocampus, several inflammatory mediators, cyclooxygenase-2 (Cox-2), IL-1 $\beta$, and $\mathrm{Ccl} 2$, are strongly induced 
within $30 \mathrm{~min}$ of SE onset, and the induction of other cytokines follows (Jiang et al., 2015). The induction of the chemokine, $\mathrm{Ccl} 2$, is noteworthy as it is involved in the recruitment of Ccr2expressing monocytes to inflamed tissue (Charo and Ransohoff, 2006; Prinz and Priller, 2010). Indeed, peripheral monocytes invade the rodent brain in the days following SE seizures, contributing to the neuroinflammatory response (Varvel et al., 2016; Tian et al., 2017).

Interestingly, blocking recruitment of monocytes to the brain after SE alleviates multiple adverse effects. After pilocarpineinduced SE, germline Ccr $2 \mathrm{KO}$ mice display greatly reduced monocyte brain infiltration and reduced hippocampal levels of the proinflammatory cytokine IL- $1 \beta$. Notably, blocking monocyte recruitment to the brain enhances weight regain, reduces $\mathrm{BBB}$ erosion, and is neuroprotective in hippocampus, identifying brain-invading monocytes as an immune cell subtype that contributes to the deleterious consequences of SE (Varvel et al., 2016).

Administration of a brain-permeable antagonist for the prostanoid EP2 receptor hours after pilocarpine- or diisopropyl fluorophosphate-induced SE produces a broad range of beneficial effects, including reduction in delayed mortality, blunted neuroinflammation, prevention of BBB opening, neuroprotection, and accelerated weight regain (Jiang et al., 2013; Rojas et al., 2015), which together mimic the effect of conditional ablation of Cox-2 from those neurons in which it is rapidly induced after pilocarpine-induced SE (Serrano et al., 2011). Thus, activation of the prostanoid EP2 receptor is a strong driver of Cox-2-mediated deleterious effects following SE. However, in these studies, EP2 receptors were globally antagonized; thus, the relevant cell types involved in EP2-driven consequences of SE remain enigmatic. Moreover, it remains unclear whether the benefits attributed to systemic EP2 antagonism also include reduced monocyte brain recruitment.

In summary, EP2 receptors are widely expressed by neurons, microglia, and other cell types throughout the brain (see Results). To determine which of the deleterious effects of Cox-2 induction after SE can be attributed to EP2 receptor activation on innate immune myeloid cells, we examined the consequences of genetically ablating the EP2 gene from CD11b-expressing myeloid cells. We also determined whether systemic pharmacologic inhibition of EP2 could prevent monocyte infiltration into the brain after SE. We showed that CD11b-driven Cre was expressed in brain endothelial cells and most circulating monocytes but only sparely in microglia. Selective deletion of immune cell EP2 receptors enhanced weight gain after pilocarpine-induced SE, alleviated early neurobehavioral deficits, prevented opening of the BBB, and selectively blunted IL-6 induction in the hippocampus. However, neuronal damage was not attenuated in the EP2 conditional KO mice after SE. By contrast, systemic EP2 antagonism after kainate-induced SE provided neuronal protection, inhibited multiple inflammatory mediators, and blocked monocyte brain infiltration. Together, these findings indicate that EP2 activation on innate immune cells contributes selectively to the sickness behaviors observed after SE, and that the benefits of EP2 antagonism include blocking monocyte infiltration.

\section{Materials and Methods}

Mice. All mice used in the current study were housed in the same rooms in Emory's animal facility during the course of the experiment, with one room designated for animal breeding and maintenance and another room solely for SE experiments. The lights were on a $12 \mathrm{~h}$ on/off cycle, and mice were fed and watered ab libitum. We obtained male
Cd11b-Cre (Boillee et al., 2006) and female EP2 flox/flox (Johansson et al., 2013) mice from K. Andreasson (Stanford University), maintained on the C57BL/6 (Charles River) background. The mice were subsequently intercrossed to propagate the colony. In the current studies, $\mathrm{Cd} 11 \mathrm{~b}$-Cre;

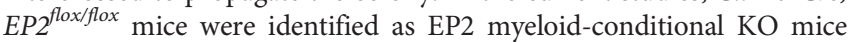
(McKO), whereas EP2-sufficient littermates $\left(\mathrm{mEP}^{+}\right)$were either homozygous $E P 2^{\text {flox/flox }}$ or heterozygous $E P 2^{+/ f l o x}$ and negative for the $C d 11 b$ Cre transgene. Of all 170 mice generated, $13.5 \%$ of the offspring were male and $\mathrm{McKO}$, and $28.2 \%$ were male and $\mathrm{mEP} 2^{+}$, in accord with the expected Mendelian ratios.

We submitted genetic material obtained from an $\mathrm{mEP}^{+}{ }^{+}$mouse to Charles River Laboratories for strain background characterization. A total of 369 single nucleotide polymorphisms spread across the genome at $7 \mathrm{Mbp}$ intervals were analyzed to generate an allelic profile for comparison with their reference inbred mouse strains. The $\mathrm{mEP} 2^{+}$mouse was a $99.6 \%$ match to C57BL/6 inbred mice from Charles River Laboratories, so the mouse strain remained essentially congenic after multiple generations of breeding at Emory.

We selected the CD11b-Cre driver to ablate EP2 from myeloid cells based on the following considerations. First, the myelomonocytic marker CD11b is expressed by both microglia and monocytes. Second, we and others have demonstrated the involvement of both microglia and infiltrating monocytes in the ensuing neuroinflammatory response following SE (Jiang et al., 2013; Vezzani et al., 2015 Varvel et al., 2016).

To create the CD11b-Cre reporter mouse line, mice hemizygous for the CD11b-Cre transgene were bred to Ai9 (The Jackson Laboratory, \#007909), creating a CD11b-Cre reporter mouse line (McKOR). Ai9 is a Cre reporter allele that has a loxP-flanked STOP cassette preventing transcription of a CAG promoter-driven red fluorescent protein variant (tdTomato), all inserted into the Gt(ROSA)26Sor locus. Ai9 mice express robust tdTomato fluorescence following Cre-mediated recombination (Madisen et al., 2010).

In $C c r 2^{r f p / r f p} \mathrm{KO}$ mice, the $C c r 2$ open reading fragment was disrupted with a cDNA encoding red fluorescent protein (RFP) (Saederup et al., 2010). The $C c r 2^{r f p / r f p}$ mice have been backcrossed to C57BL/6 (Charles River) for over 11 generations. To generate heterozygous $C c r 2^{+/ r f p}$ mice, in which monocytes are marked by RFP expression, male $C c r 2^{r f p / r f p}$ mice were bred to female C57BL/6 mice from Charles River.

Male mice were used in the current studies as, after pilocarpine, male mice more readily entered SE compared with female littermates; the pilocarpine dose required to provoke SE was usually lethal in female mice. However, when care is taken to synchronize the estrous cycle of female mice, similar results were obtained with both male and female. These results will be reported elsewhere. Attempts were made to validate four commercial EP2 antibodies using tissues from EP2 KO mice (Kennedy et al., 1999) obtained from The Jackson Laboratory, or tissues from another EP2 KO line (Hizaki et al., 1999) obtained from Tomohiro Aoki (Department of Molecular Pharmacology, Research Institute, National Cerebral and Cardiovascular Center, Suita, Osaka, Japan).

Pilocarpine injection. To minimize peripheral effects of pilocarpine, mice were injected intraperitoneally with methylscopolamine and terbutaline $(2 \mathrm{mg} / \mathrm{kg}$ each in $0.9 \%$ saline solution, pH 7.4). After $20 \mathrm{~min}$, pilocarpine hydrochloride $(328 \mathrm{mg} / \mathrm{kg}$ in $0.9 \%$ saline, freshly prepared) was injected intraperitoneally to induce SE. Control mice of each genotype received methylscopolamine and terbutaline, followed by injection of saline solution instead of pilocarpine. Seizures were classified as previously described (Borges et al., 2003; Varvel et al., 2016) and scored every $5 \mathrm{~min}$ as follows: a score of 0 represents normal behavior (walking, exploring, sniffing, grooming); a score of 1 represents immobility, staring, jumpy or curled-up hunched posture; a score of 2 represents automatisms (repetitive blinking, chewing, head bobbing, vibrissae twitching, scratching, face-washing, "star-gazing"); a score of 3 represents partial body clonus, occasional myoclonic jerks, shivering; a score of 4 represents wholebody clonus, "corkscrew" turning and flipping, loss of posture, rearing and falling; a score of 5 (SE onset) represents nonintermittent seizure activity consisting of Stage 3 or 4 repeatedly; a score of 6 represents wild running, bouncing, and tonic seizures; and a score of 7 represents death. After $1 \mathrm{~h}$, SE was interrupted by diazepam $(10 \mathrm{mg} / \mathrm{kg}$, i.p.) to reduce mortality. Saline-treated mice were also given diazepam. Mice were fed 
moistened rodent chow, monitored daily, and injected with 5\% (w/v) dextrose in lactated Ringer's solution $(0.5 \mathrm{ml}$ i.p.) when necessary.

Kainate injection and TG6-10-1 administration. Kainate was obtained from Tocris Bioscience and was dissolved at $4 \mathrm{mg} / \mathrm{ml}$ in a $0.9 \%$ saline solution, $\mathrm{pH} 7.4$, to generate a stock solution. The stock solution was diluted in $0.9 \%$ saline solution to create a working solution on injection day. Heterozygous $C c r 2^{+/ r f p}$ mice were weighed and injected with a single dose of kainate $(30 \mathrm{mg} / \mathrm{kg}$, i.p.). In mice, kainate-induced seizures consisted of distinct motor behaviors, including forelimb clonus, loss of posture, rearing, and falling. Animals presenting these behaviors with increased seizure intensity, duration, and frequency after the injection of kainate were declared to be in SE, which is characterized in the kainate model by clonic seizures accompanied by periodic rearing and falling. Behavior was scored using a modified Racine scale as previously described (Rojas et al., 2014). All mice that entered SE continued seizing for at least $60 \mathrm{~min}$; seizures usually persisted for several hours.

After $3 \mathrm{~h}$, surviving mice were randomized into two groups and received vehicle (10\% DMSO, 50\% PEG $400,40 \% \mathrm{ddH}_{2} \mathrm{O}$ ) or the $\mathrm{EP} 2$ antagonist TG6-10-1 (5 mg/kg, i.p.) at 4, 21, and $30 \mathrm{~h}$ after SE onset. The mice were killed $3 \mathrm{~d}$ after SE onset, and the brain was processed for histology, Western analysis, and gene expression as described below.

Modified Irwin test. A modified Irwin test (Irwin, 1968) was performed to assess the health and well-being of mice after pilocarpineinduced SE. The test comprised seven parameters (ptosis, lacrimation, body posture, tremors, dragging body, hyperactivity or hypoactivity, coat appearance) that can be measured simply by experimenter observation. The test was given 3 times: 48, 72, and $96 \mathrm{~h}$ after SE onset. Each parameter was scored on a 3 point scale (i.e., $0=$ normal, $1=$ mild to moderate impairment, and $2=$ severe impairment) with a total score ranging from 0 to 14 . A total score of 0 as a sum of all 7 parameters indicates a normal healthy mouse. A total score ranging from 1 to 14 indicates a mouse that is increasingly impaired.

Tissue processing. Four days after pilocarpine SE onset, mice were anesthetized deeply with isoflurane, perfused through the heart with PBS solution, and their brains rapidly removed from the cranium. The brain was immediately bisected through the midline, and the left hemisphere was fixed for $24 \mathrm{~h}$ in $4 \%(\mathrm{w} / \mathrm{v}) \mathrm{PFA}$ at $4^{\circ} \mathrm{C}$. The hippocampus and overlying cortex were dissected from the right half of the brain, immediately frozen on dry ice and stored at $-80^{\circ} \mathrm{C}$ for RNA isolation and Western blot analysis, respectively.

Fluoro-Jade B (FJB) labeling. After $24 \mathrm{~h}$ in $4 \%$ PFA, the left hemisphere was cryoprotected in $30 \%(\mathrm{w} / \mathrm{v})$ sucrose in PBS solution. Brains were subsequently frozen in 2-methylbutane and sectioned coronally at $25 \mu \mathrm{m}$ by using a freezing/sliding microtome. Every 12th section for a total of five or six sections from each hemisphere was used for FJB staining to label degenerating neurons. Sections were mounted on Superfrost Plus Microscope Slides (Thermo Fisher Scientific) and allowed to air-dry overnight. Sections were immersed in $0.06 \%$ potassium permanganate for $15 \mathrm{~min}$ with gentle agitation, rinsed for $1 \mathrm{~min}$ in distilled water, and then transferred to the FJB staining solution $(0.0001 \% \mathrm{w} / \mathrm{v}$ FJB in distilled water with $0.1 \%$ acetic acid) for $30 \mathrm{~min}$ in the dark with gentle agitation. Sections were rinsed with three 1 min changes of distilled water and air-dried. The slides were immersed in xylene and then coverslipped with D.P.X. mounting media (Sigma Millipore). Sections between bregma -1.34 and -2.40 were examined with a fluorescent microscope.

Following FJB staining, images were obtained from three hippocampal areas (hilus, CA1, CA3) in each section. A researcher unaware of mouse genotype and experimental conditions counted the number of FJB-positive neurons in the hippocampus. Only positive neurons with a near-complete cell body shape and size were tabulated. Cell counts were expressed as the total number of FJB-positive cells per section for each region. The inter-rater reliability was determined by measuring pairwise correlation of the average number of FJB-positive neurons counted in each animal in the study. The Pearson coefficient was 0.99 with a slope of 0.91 , indicating excellent reliability between trained personnel.

Immunohistology. For immunofluorescence staining, sections were blocked for $45 \mathrm{~min}$ in $5 \%$ goat serum and incubated overnight at $4^{\circ} \mathrm{C}$ with antibodies against rabbit anti-EP2 (1:1000, Abcam, ab167171), rat anti-CD11b (1:1000, Millipore, clone M1/70), or rat anti-CD31 (1:250,
BD PharMingen, 557355). Primary antibody incubation was followed by extensive washing with PBS, incubation with fluorescent AlexaFluor secondary antibodies (1:250, Invitrogen) for $45 \mathrm{~min}$, and washing in PBS. Stained brain sections were mounted on glass slides and mounting medium with DAPI and antifade (Vector) was applied. Images were acquired with an Olympus FV1000 confocal laser scanning microscope or Carl Zeiss AxioObserver A1 epifluorescence microscope equipped with an AxioCam MRc5 camera. Maximum intensity projections were created using ImageJ software.

Western blot analysis of albumin. Cerebral cortices from saline-perfused mice were homogenized in 10 volumes of RIPA buffer with protease and phosphatase inhibitors (Thermo Fisher Scientific). Brain homogenates were centrifuged at $14,000 \times g$ for $30 \mathrm{~min}$ at $4^{\circ} \mathrm{C}$ to remove nuclei and cell debris. The supernatant was subsequently sonicated to shear DNA. Brain protein was run on a 4\%-20\% Mini-PROTEAN TGX Gel and electroblotted onto PVDF membranes (Millipore). Membranes were blocked for $1 \mathrm{~h}$ at room temperature with Odyssey blocking solution (LI-COR), then incubated overnight at $4^{\circ} \mathrm{C}$ with primary antibodies for albumin (1:1000; Cell Signaling) and GAPDH (1:10,000; Calbiochem), followed by $1 \mathrm{~h}$ incubation with polyclonal IRDye secondary antibodies $680 \mathrm{LT}$ and $800 \mathrm{CW}$ (1:15,000; LI-COR). The blots were imaged by a LI-COR imaging system using channels 700 and 800 . Because all samples could not be run on the same gel, one sample was run on each blot for interblot normalization. Band intensity was measured and corrected for nearby background intensity by the LI-COR software. The value of the albumin/GAPDH ratio for each sample was then determined. The average ratio for selected groups was compared by ANOVA with post hoc Sidak adjustment. The fold change for each group was plotted on a linear scale.

Myeloid cell isolation and flow cytometry. SE was induced with pilocarpine in WT mice on the C56BL/6 background from Charles River as described earlier. Four days after SE, the mice were perfused with Hanks' buffered salt solution, the brains and blood were removed, and mononuclear cells were separated with a 30\%/70\% Percoll gradient as previously reported (Cardona et al., 2006; Varvel et al., 2016). Single-cell suspensions were stained with anti-CD11b-PerCP (M1/70; BioLegend) and anti-Ly6C-FITC (AL21; BD PharMingen). Spleens were harvested from $\mathrm{mEP}_{2}{ }^{+}$and $\mathrm{McKO}$ mice. Splenocytes were obtained by passing the spleen contents twice through a $70 \mu \mathrm{m}$ mesh with the aid of syringe handle followed by lysing the red blood cells with AKC lysing buffer (Thermo Fisher Scientific). Splenocytes were then washed with cold PBS containing 5\% FBS. Single-cell suspensions were stained with antiCD11b-PerCP (M1/70; BioLegend) antibodies. Cells were sorted on a FACSAria II (BD) running Diva6. Data were analyzed with FlowJo software (Tree Star).

RNA extraction and amplification from sorted myeloid cells. RNA was extracted from using RNeasy spin columns (QIAGEN) or QuickRNA MiniPrep (Zymo) according to manufacturer's instructions. RNA samples were analyzed with the BioAnalyzer (Agilent Technologies). Only samples with an RNA integrity value of at least 7 were selected for further analysis. For microglia and monocytes, RNA from 24 of 26 mice met this criterion. For splenocytes, RNA from all 6 mice met this criterion with a mean value of 8.95 . One round of poly-A RNA amplification was performed on each sample by using MessageBOOSTER cDNA synthesis kit for qPCR (Lucigen) following the manufacturer's instructions. Gene-expression analysis was performed as described above. The geometric mean of the cycle thresholds ( $C_{t}$ values) for $\beta$-actin, GAPDH, and HPRT1 was used as internal RNA-level control for relative quantification for the microglia and monocytes. The $\mathrm{C}_{t}$ value for $\mathrm{CD} 11 \mathrm{~b}$ was used as internal control of relative expression of the splenocytes.

Validation of EP2 antibody. We first compared Western blots from tissues of EP2-sufficient, heterozygous EP2, and global EP2 KO mice. Brain and kidney from perfused global EP2 KO mice were kindly provided by Richard Breyer (Vanderbilt University) (Kennedy et al., 1999). The kidney was homogenized and centrifuged as described above. Membranes were blocked for $1 \mathrm{~h}$ at room temperature with Odyssey blocking solution (LI-COR), then incubated overnight at $4^{\circ} \mathrm{C}$ with primary rabbit monoclonal antibodies that are directed to the EP2 coding sequence that overlaps the remaining genomic sequence in EP2 $\mathrm{KO}$ 
mice (1:1000; Abcam, ab167171) followed by incubation with polyclonal IRDye secondary antibodies (1:15 000; LI-COR). The blots were imaged by a LI-COR imaging system using channels 700 and 800 . To further characterize the performance of the Abcam EP2 antibody, we stained a variety of tissues or cell lines that were selected by qRT-PCR as being very low or high expressers of EP2.

Three other EP2 antibodies from Lifespan Biosciences (LS-C406698, 1:200; LS-B6048, 1:750; or LS-C200473, 1:750) were tested. Both polyclonal antibodies LS-C200473 and LS-B6048 detected a protein migrating at $\sim 42 \mathrm{kDa}$ in brain, uterine, and kidney homogenates obtained from EP2 KO mice. These two antibodies detected no discernible proteins of lower molecular weight. Polyclonal antibody LS-C406698 detected a protein migrating at $\sim 60 \mathrm{kDa}$ in kidney and uterine homogenates, but not in homogenates of heart and brain, obtained from $\mathrm{mEP} 2^{+}$mouse tissue. In addition, a band of similar size was detected in BV-2 cells stably overexpressing human EP2 as well as parent BV-2 cells expressing little or no endogenous mouse EP2. We also observed a band migrating near the 37 $\mathrm{kDa}$ marker in all tissue and cellular homogenates, including the EP2 $\mathrm{KO}$ brain. We conclude these three polyclonal antibodies are unreliable.

Cell culture. Two rat C6 glioma cell lines stably expressing human prostanoid receptors DP1 and EP2 were created in the laboratory and grown in DMEM (Invitrogen) supplemented with $10 \%$ (v/v) FBS (Invitrogen), $100 \mathrm{U} / \mathrm{ml}$ penicillin, $100 \mu \mathrm{g} / \mathrm{ml}$ streptomycin (Invitrogen), and $0.5 \mathrm{mg} / \mathrm{ml} \mathrm{G418} \mathrm{(Invitrogen)} \mathrm{(Jiang} \mathrm{et} \mathrm{al.,} \mathrm{2013).} \mathrm{Fixed} \mathrm{cells} \mathrm{were}$ stained with anti-EP2 antibody (1:1000; Abcam, ab167171) followed by incubation with AlexaFluor secondary antibodies.

$q R T-P C R$. Total RNA from mouse hippocampus was isolated by using TRIzol (Invitrogen) with the PureLink RNA Mini Kit (Invitrogen). RNA concentration and purity were measured by A260 value and the A260/A280 ratio, respectively. We typically recovered 5-15 $\mu$ g RNA from each hippocampus with A260/280 ratio=2.1-2.2. First-strand cDNA synthesis was performed with $1.0 \mu \mathrm{g}$ of total RNA, using qScript cDNA SuperMix (\#95048, Quantabio) in a reaction volume of $20 \mu \mathrm{l}$ at $25^{\circ} \mathrm{C}$ for $5 \mathrm{~min}$, then $42^{\circ} \mathrm{C}$ for $30 \mathrm{~min}$. The reaction was terminated by heating at $85^{\circ} \mathrm{C}$ for $5 \mathrm{~min}$. qRT-PCR was performed by using $8 \mu \mathrm{l}$ of $50 \times$ diluted cDNA, 0.1-0.5 $\mu \mathrm{M}$ of primers, and $2 \times$ iQ SYBR Green Supermix (Bio-Rad Laboratories), with a final volume of $20 \mu$ l, in the iQ5 Multicolor Real-Time PCR Detection System (Bio-Rad). Cycling conditions were as follows: $95^{\circ} \mathrm{C}$ for 2 min followed by 40 cycles of $95^{\circ} \mathrm{C}$ for $15 \mathrm{~s}$ and then $60^{\circ} \mathrm{C}$ for $1 \mathrm{~min}$. Melting curve analysis was used to verify single-species PCR product. Fluorescent data were acquired at the $60^{\circ} \mathrm{C}$ step. The geometric mean of the $\mathrm{C}_{\mathrm{t}}$ values for $\beta$-actin, GAPDH, and HPRT1 was used as internal RNA-level control for relative quantification (Tables 1 and 2). Samples without cDNA served as the negative controls. The mean efficiency of our PCR reactions was $94.6 \pm 1.7 \%$ with a range of $83 \%-105 \%$. After adjusting $C_{t}$ values for individual analytes by subtracting the geomean $C_{t}$ of three housekeeping genes, the $\Delta C_{t}$ values were flat across the dilution series, further validating the linearity of this qRT-PCR assay.

Stereological assessment of monocyte number. Numbers of $\mathrm{RFP}^{+}$ monocytes were assessed on sets of every 12th systematically sampled 25$\mu \mathrm{m}$-thick coronal immunostained section through the hippocampus. The sections were stained with rabbit polyclonal antibody to RFP (1:1000, Abcam). Stereological analysis was performed with the aid of the Stereologer software (Stereo Investigator 6, MBF Bioscience) and a motorized x-y-z stage coupled to a video microscopy system. The optical fractionator technique was used with 3D dissectors (area, $350 \times 350 \mu \mathrm{m}^{2}$; height, $8 \mu \mathrm{m}$; guard height, $2 \mu \mathrm{m}$; counting frame, $50 \times 50 \mu^{2}$ ) (Long et al., 1998). RFP ${ }^{+}$monocytes with complete soma within the dissector volume were counted.

Immunophenotyping of blood-borne cells from McKOR mice. Blood was obtained from deeply anesthetized McKOR mice via cardiac puncture with an EDTA-lined syringe and smeared on glass slides. Dried blood smears were fixed in chilled $\left(-20^{\circ} \mathrm{C}\right)$ methanol for $30 \mathrm{~s}$ and stored at $-80^{\circ} \mathrm{C}$. Before staining, the slides were allowed to warm to room temperature. Immunocytostaining was performed using primary antibodies to RFP (1:1000, Abcam), CD11b (1:500, Millipore), and EP2 (1:1000, Abcam) followed by secondary AlexaFluor antibodies (1:250, Invitrogen). Sections were coverslipped under Mounting Medium with DAPI and antifade (Vector).
Table 1. $C_{t}$ values and geometric means of housekeeping genes in four groups from hippocampus $4 \mathrm{~d}$ after treatment with saline or pilocarpine

\begin{tabular}{lllll}
\hline Genes & $\mathrm{mEP2}^{+}$basal & McK0 basal & $\mathrm{mEP2}^{+}$pilocarpine & McK0 pilocarpine \\
\hline HPRT1 & $23.6 \pm 0.2$ & $23.8 \pm 0.4$ & $24.0 \pm 0.3$ & $23.8 \pm 0.2$ \\
$\beta$-actin & $22.0 \pm 03$ & $21.6 \pm 0.2$ & $21.4 \pm 0.3$ & $20.8 \pm 0.3$ \\
GAPDH & $18.1 \pm 0.1$ & $17.9 \pm 0.1$ & $18.3 \pm 0.2$ & $17.9 \pm 0.1$ \\
Geomean & $21.1 \pm 0.2$ & $20.9 \pm 0.2$ & $21.1 \pm 0.2$ & $20.7 \pm 0.2$ \\
\hline
\end{tabular}

Data are the mean \pm SEM ( $n=8 /$ group)

Table 2. $C_{t}$ values and geometric means of housekeeping genes from hippocampus $3 \mathrm{~d}$ after SE

\begin{tabular}{lll}
\hline Genes & Kainate vehicle & Kainate TG6-10-1 \\
\hline HPRT1 & $25.2 \pm 0.3$ & $25.5 \pm 0.3$ \\
$\beta$-actin & $23.1 \pm 0.5$ & $22.4 \pm 0.6$ \\
GAPDH & $20.7 \pm 0.4$ & $20.5 \pm 0.2$ \\
Geomean & $22.9 \pm 0.2$ & $22.7 \pm 0.3$ \\
\hline
\end{tabular}

Data are the mean \pm SEM ( $n=5 /$ group)

Experimental design and statistical analysis. The primary objective of the study was to examine the consequences of cell-specific prostaglandin EP2 receptor signaling in innate immune myeloid cells after SE using conditional KO strategies. Therefore, the effects of SE in McKO mice were compared with the effects of SE in $\mathrm{mEP} 2^{+}$littermates. Prospective power analysis was based on the variability in gene induction encountered in our previous studies (Jiang et al., 2013, 2015; Varvel et al., 2016) and our desire to observe at least a $30 \%$ difference in gene induction between the two genotypes, if present. With these considerations, 8 mice/genotype/treatment were used. Before induction of SE, McKO and $\mathrm{mEP} 2^{+}$mice were each randomized into two groups: saline solutiontreated and pilocarpine-treated.

One-way ANOVA was used for Figures $2 B, 3 B, 4 B, C, 5 C, 6 D$, and $9 G$, and two-way ANOVA for Figures $1 E, F$, and $9 C$, followed by comparison of selected means with Sidak or Dunnett's correction for multiple comparisons as appropriate. Unpaired $t$ tests were used for comparing two groups. For analysis of gene induction, the mean $\Delta \Delta \mathrm{C}_{\mathrm{t}}$ values were compared between selected groups. After statistical analysis, individual $\Delta \Delta \mathrm{C}_{\mathrm{t}}$ values from each sample group were converted to fold change by $2^{\Delta \Delta \mathrm{Ct}}$, and the fold change from each group was plotted on a logarithmic scale. Results are expressed as mean \pm SEM. Statistical analysis was performed using GraphPad version 6 (GraphPad Software). For all analyses, the differences were considered to be statistically different if $p<0.05$.

For the systemic EP2 antagonism experiments, all mice were subject to kainic acid and then randomized in selected experiments to receive TG6-10-1 or vehicle. Just before performing saline $(+)$ statistical tests, potential outliers were sought by Grubb's test for removal; no outliers were identified.

To minimize experimenter bias, analysis of results that require judgment (e.g., counting FJB cells) was done blinded to experimental group; and when multiple investigators participated, we determined the interrater reliability. We also conducted extensive tests to validate the selectivity of the EP2 antibody used, we verified that the background mouse strain was stable after $>10$ generations at Emory, and we compared the intrinsic efficiency of the PCR reactions for the various analytes examined.

\section{Results}

Systemic administration of pilocarpine induces typical SE in the absence of EP2 expression in innate immune myeloid cells

To examine the role of EP2 activation in innate immune myeloid cells (microglia and monocytes), we generated EP2 conditional $\mathrm{KO}$ mice by crossing Cd11b-Cre mice (Boillee et al., 2006) with $E P 2^{f l f l}$ mice (Johansson et al., 2013) to create animals lacking 

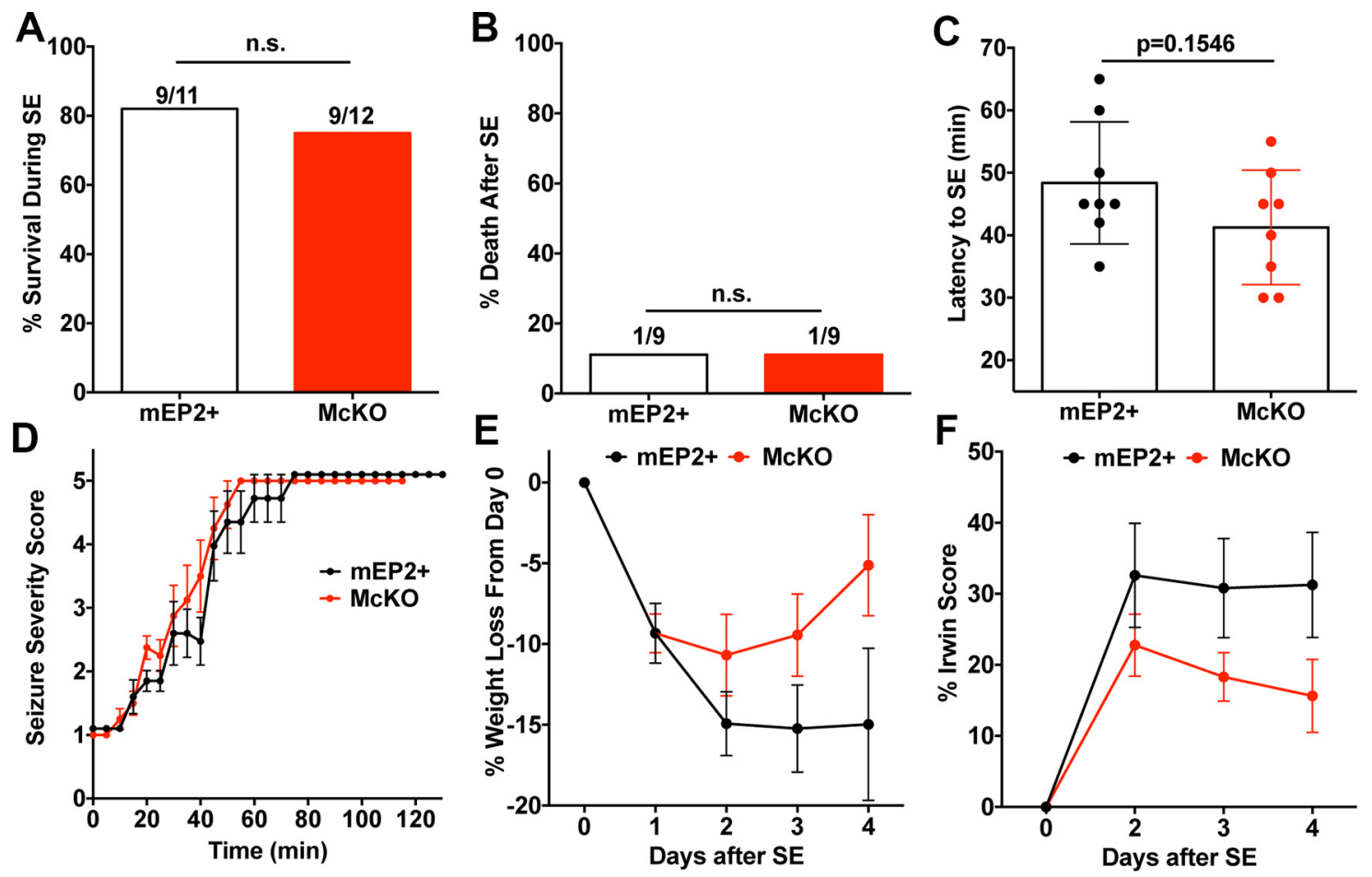

Figure 1. Mouse behavior during SE and in the days following seizure interruption. $\boldsymbol{A}$, The survival during SE was similar in both genotypes $\left(n=9\right.$ of $11 \mathrm{mEP} 2^{+} ; n=9$ of $12 \mathrm{McK} 0$; Fisher's exact test). $\boldsymbol{B}$, Mortality after SE, defined as deaths that occurred during the $4 \mathrm{~d}$ after interruption of SE, was identical between the two genotypes (1 of 9 mice in both mEP2 ${ }^{+}$and McK0). $C$, The latency to SE, as judged by the behavioral seizure score, was similar in $\mathrm{mEP2}^{+}$and McKO mice ( $n=8 /$ genotype, unpaired $t$ test). Error bars indicate mean \pm SEM. $\boldsymbol{D}$, The behavioral seizure score was tabulated every $5 \mathrm{~min}$ until the seizure was interrupted by diazepam $1 \mathrm{~h}$ after SE onset in $\mathrm{mEP} 2^{+}$and McKO mice $\left(n=8 /\right.$ genotype; open squares represent $\mathrm{mEP2}{ }^{+}$; red squares represent MCKO). The temporal evolution of SE was similar in both genotypes. The average behavioral scores are represented as mean \pm SEM. $E$, McKO mice (red circles) regained lost weight faster than $\mathrm{mEP2}^{+}$mice (black circles) ( $n=8 / \mathrm{d} /$ genotype, two-way ANOVA, the effect of genotype, $\left.F_{(1,56)}=6.511, p=0.0135\right)$. $\boldsymbol{F}$, Comparison of the modified Irwin scores taken on days $2-4$ revealed improved scores in McKO ( $n=8$, red circles) compared with $\mathrm{mEP}^{+}\left(n=8\right.$, open circles) (two-way ANOVA, the effect of genotype, $\left.F_{(1,42)}=6.732, p=0.0130\right)$. Data are shown as a percent of the maximum possible score, with 0 indicating a normal, healthy mouse. n.s., not significant.

EP2 in myeloid cells (McKO) and their EP2-sufficient control littermates $\left(\mathrm{mEP}^{+}\right)$. Upon entering SE, 2 of $11 \mathrm{mEP} 2^{+}$mice died while 3 of $12 \mathrm{McKO}$ mice died in SE (Fig. $1 A$ ). Of the 18 surviving mice, 1 mouse died in each group in the following $4 \mathrm{~d}$ after interruption of SE by diazepam (Fig. $1 B$ ), indicating that the absence of myeloid cell EP2 did not modify either mouse survival during SE or delayed mortality in the days following SE.

Next, we evaluated the latency to SE in the 16 mice that survived until the $4 \mathrm{~d}$ time point. On average, the $\mathrm{mEP} 2^{+}$sufficient mice entered SE $\sim 48 \mathrm{~min}$ after pilocarpine administration, whereas the $\mathrm{McKO}$ mice entered SE $\sim 41 \mathrm{~min}$ after pilocarpine, a difference not statistically significant (Fig. 1C). In addition, the temporal evolution of behavior seizure severity scores was similar between the $\mathrm{mEP}^{+}$and McKO groups (Fig. 1D). Together, these findings indicate that the absence of EP2 in innate immune myeloid cells does not alter mortality during SE, delayed mortality after SE, or seizure susceptibility. Thus, the consequences of SE can be compared between $\mathrm{mEP} 2^{+}$and $\mathrm{McKO}$ mice.

\section{McKO mice display less behavioral deterioration following SE}

Previously, we have shown that, during the first 24-48 $\mathrm{h}$ following SE, rodents lose $10 \%-20 \%$ of their body weight and then slowly begin to recover in the following days (Jiang et al., 2013; Rojas et al., 2015; Varvel et al., 2016). In the current study, both $\mathrm{mEP}^{+}$and $\mathrm{McKO}$ mice lost $\sim 9 \%$ of their body weight in the $24 \mathrm{~h}$ after pilocarpine SE onset. By the second day, $\mathrm{mEP}^{+}$mice continued to lose weight, and they never recovered their lost body weight, such that by the fourth day the $\mathrm{mEP} 2^{+}$animals on average had lost $\sim 15 \%$ of their original body weight (Fig. $1 E$ ). In contrast, $\mathrm{McKO}$ mice began to regain their lost weight by the third day. By the fourth day, the McKO had regained all but $\sim 5 \%$ of their original body weight before SE. There was a statistically significance difference in weight change from day 1 to day 4 between genotypes $(p=0.014)$.

Using a modified Irwin test, we determined the effect of eliminating EP2 from innate immune myeloid cells on a selected subset of normal behaviors. The data were plotted as a mean percent of the maximum possible score for each genotype following SE. Higher scores reflect more functional impairment. In general, modified Irwin scores were high $24 \mathrm{~h}$ after SE and then declined toward normal regardless of genotype. $\mathrm{McKO}$ mice showed lower modified Irwin scores than $\mathrm{mEP} 2^{+}$mice, suggesting less deterioration of normal physiological characteristics in EP2-KO mice (Fig. $1 F$ ). Relief from ptosis and abnormal posture had a dominant contribution to the observed behavioral differences between genotypes. Together, these findings indicate that $\mathrm{McKO}$ mice show less behavioral deficit compared with their littermate $\mathrm{mEP} 2^{+}$counterparts in the days following SE, suggesting that myeloid cell EP2 signaling has a deleterious role in mouse well-being after SE.

\section{Serum albumin levels in the cortex are elevated after SE in $\mathrm{mEP2}^{+}$mice, but not in McKO mice}

Insults to the brain, including SE, can degrade the BBB as manifested by extravasation of blood-derived proteins, such as serum albumin. The ensuing penetration of albumin into the brain tissue has been purported to trigger epileptogenesis (Ivens et al., 2007; Varvel et al., 2015). Global EP2 inhibition with a selective 
antagonist prevents albumin extravasation into the cortex after pilocarpine SE (Jiang et al., 2013), but the relevant cell types were not identified. Serum albumin was detected in cortical homogenates obtained from $\mathrm{mEP} 2^{+}$mice perfused with PBS $4 \mathrm{~d}$ following pilocarpine-induced SE, compared with minimal albumin detected in cortex of saline-treated $\mathrm{mEP}^{+}$control mice (Fig. $2 A$ ). In contrast, there was no significant elevation of albumin in cortices from pilocarpine-treated $\mathrm{McKO}$ mice compared with saline-treated $\mathrm{McKO}$ controls, and no difference between salinetreated $\mathrm{mEP}^{+}$and saline-treated $\mathrm{McKO}$ cortices (Fig. 2B). Visual inspection of Figure $2 C$ reveals an inconsistent elevation of cortical albumin in less than half the animals. Although this was statistically insignificant, the power to have detected the mean difference was moderate $(65 \%)$. Figure $2 C$ shows an alternate analysis that avoids significance testing; the $95 \% \mathrm{CI}$ of the point-by-point difference in a bootstrapped resampling distribution (Fig. 2C, bottom) reinforces that conclusion that pilocarpine elevates cortical albumin in the EP2-sufficient mice but not in the $\mathrm{McKO}$ mice. These findings altogether suggest that EP2 signaling in innate immune myeloid cells enhances erosion of the $\mathrm{BBB}$ after pilocarpine-induced SE.

\section{Ablation of myeloid cell EP2 is not neuroprotective after SE}

We assessed the degree of neuronal damage 4 dafter pilocarpine-induced SE by examining FJB staining in hippocampal brain sections. As expected, FJB staining was encountered in the CA1 and CA3 hippocampal subfields as well as the hilar region of the dentate gyrus in both $\mathrm{mEP}^{+}$and McKO mice after SE. Surprisingly, in the CA1 subfield, the number of damaged neurons appeared to be similar regardless of genotype (Fig. 3A). This impression was confirmed by counting the number of $\mathrm{FJB}^{+}$pyramidal neurons in the CA1 and CA3 subfields as well as the hilar neurons. No significant differences in number of damaged neurons were encountered (Fig. 3B).

\section{Hippocampal induction of IL-6 is selectively blunted in McKO mice after SE}

To gain further insight into the role of myeloid cell EP2 signaling after SE, we investigated the expression profile of a panel of inflammatory mediators in hippocampus from $\mathrm{mEP}^{+}$and McKO mice. qRT-PCR was performed on hippocampal tissue to measure the levels of inflammatory mediators as well as glial markers previously demonstrated to be induced in the mouse hippocampus after pilocarpine SE (Jiang et al., 2013, 2015; Serrano et al., 2011; Varvel et al., 2016). The basal mRNA levels of the inflammatory mediators and glial markers were nearly identical in hippocampus obtained from saline solutiontreated $\mathrm{mEP}^{+}$and McKO animals (Fig. 4A). The mRNA levels of the inflammatory mediators IL- $1 \beta$, TNF $\alpha$, and $\mathrm{Ccl} 2$ were all

A

B
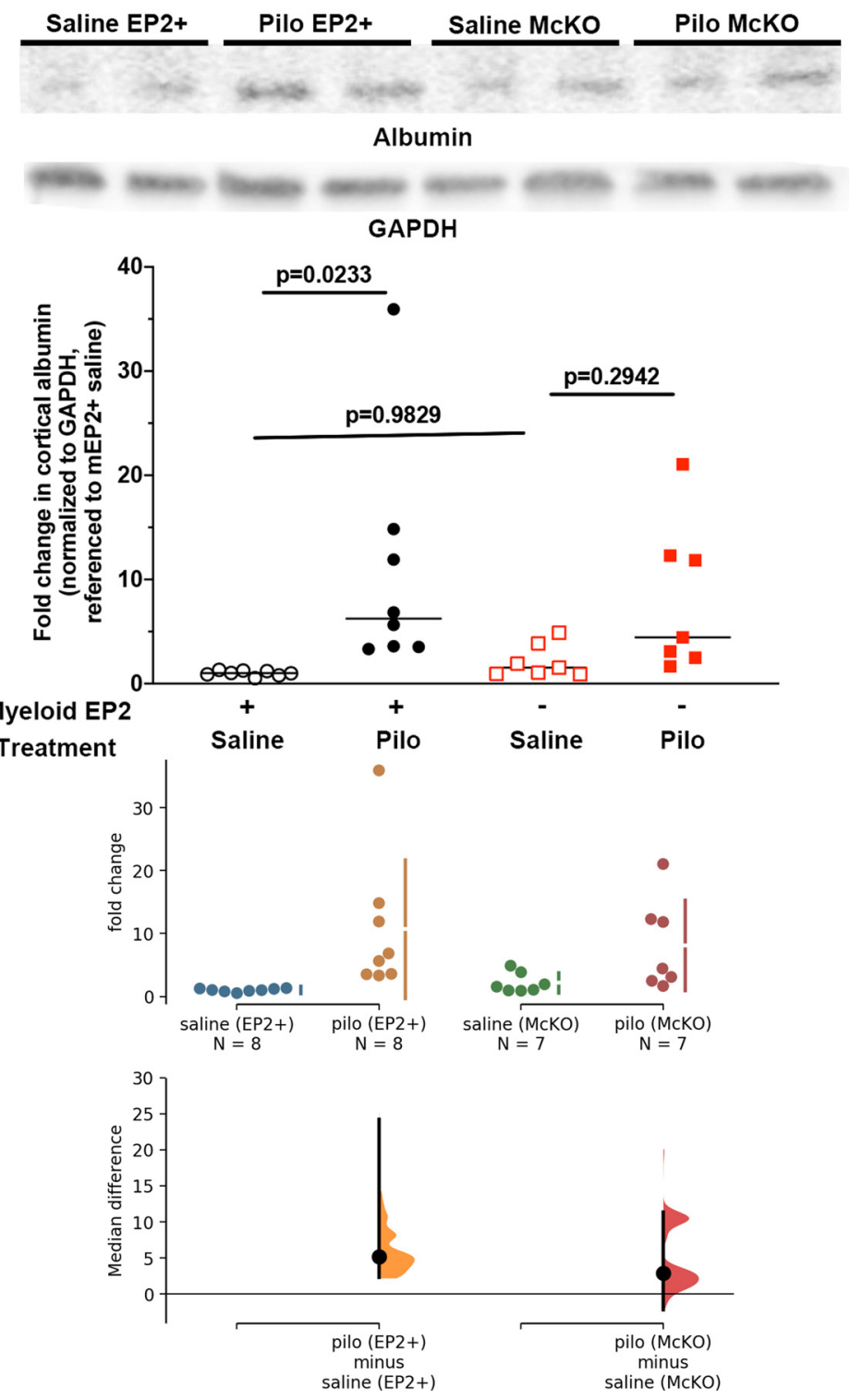

Figure 2. Serum albumin extravasation into the brain $4 \mathrm{~d}$ after SE was used to evaluate the integrity of the BBB. $A$, Albumin protein levels in cortical homogenates of saline-treated and pilocarpine-treated $\mathrm{mEP}^{+}$and McKO mice were measured by Western blot with GAPDH as loading control. Two representative samples near the mean of each group are shown. $\boldsymbol{B}$, Normalized band intensity of the albumin protein relative to that of GAPDH and referenced to the mean albumin/GAPDH ratio in saline-treated $\mathrm{mEP2}{ }^{+}$mice. Two statistical outliers were identified by the Grubb's test and removed: one from the saline solution-treated McKO group and the other from the pilocarpine-treated McK0 group. The albumin/GAPDH ratios were compared between each experimental group by one-way ANOVA $\left(F_{(3,26)}=2.339\right.$, $p=0.0241$ ) with post hoc Sidak test with selected pairs. Horizontal line in the boxes indicates the median value. Each symbol represents data from a single mouse. The achieved power to have detected a real difference between the saline solution-treated mEP2 ${ }^{+}$and saline solution-treated McK0 mice was $65 \%$. C, Cumming estimation plots (Ho et al., 2019) of median differences in fold change. Top, Gapped vertical lines indicate $95 \%$ Cls with the mean value at the gaps in the lines. Bottom, Each mean difference is plotted as a bootstrap resampling distribution. Dots represent mean differences. Ends of the vertical error bars indicate $95 \% \mathrm{Cl}$.

induced in $\mathrm{mEP}^{+}$and $\mathrm{McKO}$ mice at similar levels, although variability in TNF $\alpha$ and $\mathrm{Ccl} 2$ mRNA levels could have masked a 50\%-70\% suppression. However, the induction of hippocampal IL-6 was almost completely prevented in the McKO mice subjected to pilocarpine-induced SE compared with $\mathrm{mEP}^{+}$mice ( $p=0.0025$; Fig. $4 B$ ). COX-2 induction (Jiang et al., 2015) had subsided in these mice by $4 \mathrm{~d}$ after SE. No significant differences were encountered in the glial markers examined between $\mathrm{mEP}^{+}$and McKO mice (Fig. 4C). 

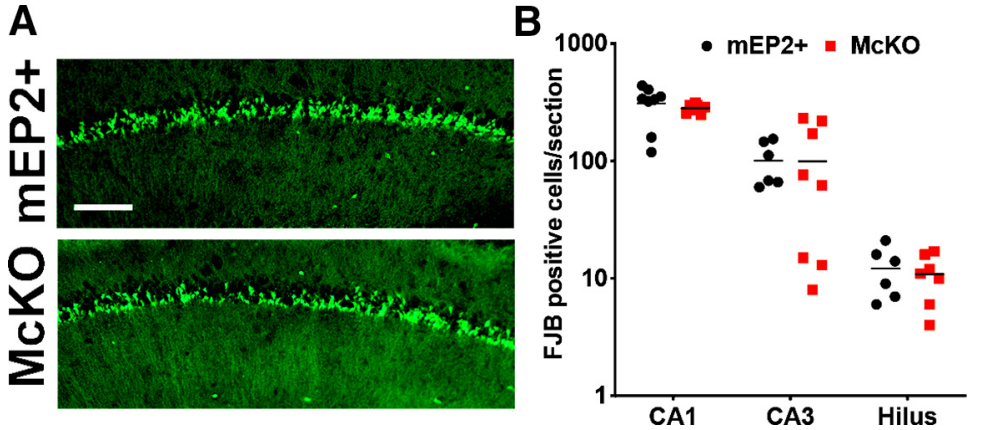

Figure 3. Neuroprotection is not observed in McKO mice after SE. A, FJB staining in hippocampal tissue sections $4 \mathrm{~d}$ after pilocarpine SE shows similar numbers of damaged neurons in the CA1 subfield of $\mathrm{mEP2}^{+}$compared with McKO littermates. Scale bar, $200 \mu \mathrm{m}$. B, Plot of the number of FJB ${ }^{+}$cells in hippocampal cell layers. Each symbol represents data from a single mouse. Horizontal bars represent the mean of each group (CA1 mEP2 ${ }^{+} n=8$; CA1 McKO $n=7$, statistical outlier removed; $\mathrm{CA}^{2} \mathrm{mEP2}^{+} n=6$, two samples too damaged to count; CA3 McK0 $n=8$; hilus $\mathrm{mEP2} 2^{+} n=6$, one sample too damaged to count; statistical outlier removed; hilus McKO $n=7$, statistical outlier removed). The outliers, if retained, would not have changed the interpretation. One-way ANOVA $\left(F_{(5,36)}=26.8\right.$, $p<0.0001)$ found significant differences among the groups. However, there were no significant differences between genotypes in any of the three regions, using a post hoc Sidak multiple-comparisons test. The power to have detected previously found levels of neuroprotection was $99.9 \%$ for CA1, $23 \%$ for CA3, and $34 \%$ for hilus.
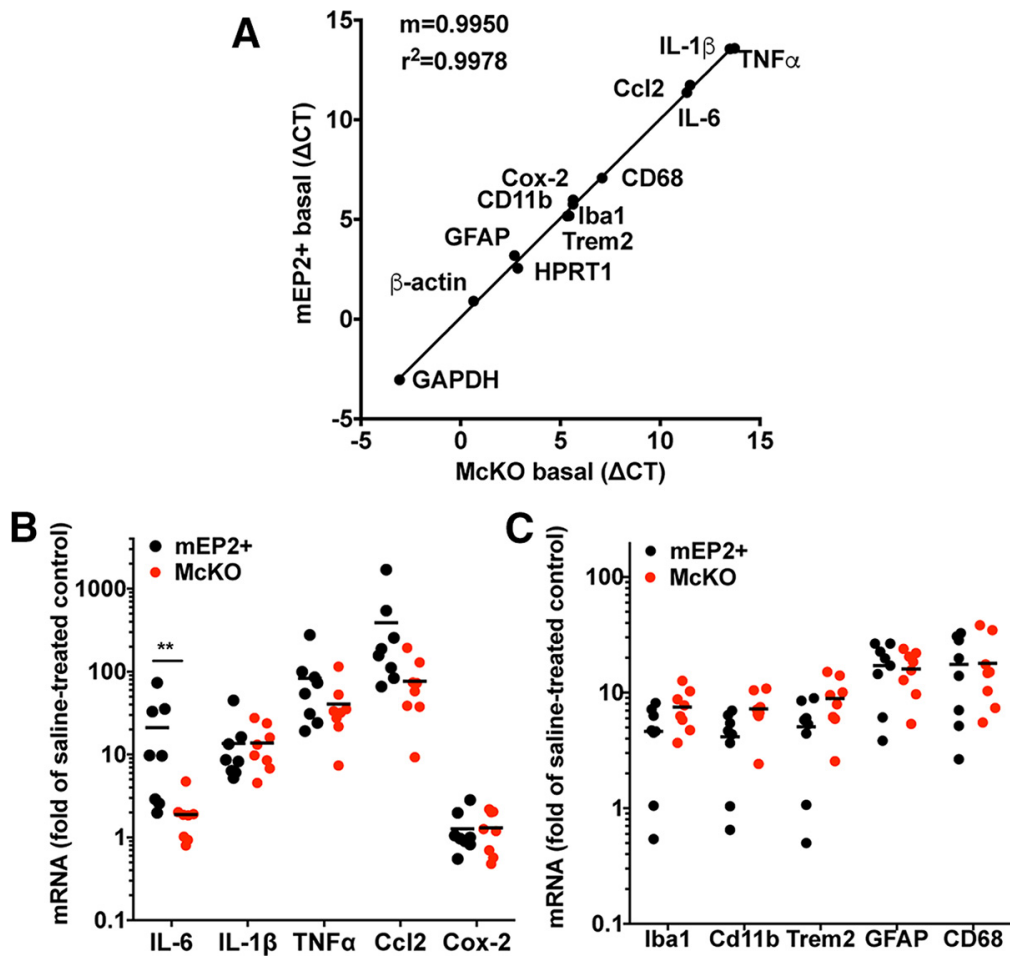

Figure 4. Expression of inflammatory mediators and glial markers in hippocampus $4 \mathrm{~d}$ after SE. $A$, The basal hippocampal levels of mRNA encoding inflammatory mediators and glial markers were similar in $\mathrm{mEP2}{ }^{+}$and $\mathrm{McKO}$ animals injected with saline solution. Each symbol represents the mean $\Delta \mathrm{CT}$ of 8 mice of both genotypes. $\boldsymbol{B}$, Horizontal line indicates mean fold induction of the inflammatory mediators in hippocampus and is plotted for $\mathrm{mEP2}^{+}(n=8)$ and McKO $(n=8)$ mice $4 \mathrm{~d}$ after SE. Each symbol represents an individual mouse, with induction referenced to the mean of the appropriate saline solution-treated group (one-way ANOVA, $F_{(9,70)}=22.98$, $p<0.0001)$. A significant difference was found in IL-6 $(* * p=0.0025)$ induction after Sidak. No significant changes were encountered in glial markers (C).

Cre recombinase robustly ablates EP2 from $\mathrm{CD} 11 b^{+}$ splenocytes; monocytes express high levels of EP2

We sought to determine the mRNA levels of EP2 in $\mathrm{CD}_{11 \mathrm{~b}^{+}}$ splenocytes. Nearly $60,000 \mathrm{CD} 11 \mathrm{~b}^{+}$cells were obtained from each spleen of $3 \mathrm{mEP}^{+}$and $3 \mathrm{McKO}$ mice by flow cytometry sorting (Fig. 5A). To assess relative levels of $\mathrm{CD}_{11 \mathrm{~b}^{+}}$splenocyte
EP2 mRNA in both genotypes, the $\mathrm{C}_{t}$ values for $\mathrm{EP} 2$ and $\mathrm{CD} 11 \mathrm{~b}$ in $\mathrm{mEP} 2^{+}$splenocytes were compared with those in McKO splenocytes (Fig. $5 B)$. The mean $\mathrm{C}_{\mathrm{t}}$ value for EP2 in $\mathrm{mEP} 2^{+}$splenocytes was 28.39. In contrast the EP2 mRNA level was below background in each of the 3 $\mathrm{McKO}$ mice, suggesting a near complete loss of EP2 mRNA in McKO CD11b ${ }^{+}$splenocytes. We conclude EP2 is ablated from nearly all CD11b ${ }^{+}$ blood immune cells in the McKO mouse.

To evaluate the levels of EP2 mRNA in brainresident microglia and brain-infiltrating monocytes, FACS-purified myeloid cell populations were isolated from WT brain homogenates $4 \mathrm{~d}$ after pilocarpine SE based on their differential expression of Ly6C and CD11b, wherein microglia are $\mathrm{CD}_{11 \mathrm{~b}^{+}}$and exhibit low levels of Ly6C, and brain-invading monocytes are also $\mathrm{CD} 11 \mathrm{~b}^{+}$ but with higher levels of Ly6C than microglia.

EP2 levels in microglia and monocytes from the pilocarpine SE brain and blood monocytes from saline solution-treated control mice were normalized to EP2 levels in microglia from saline-treated control mice. Notably, EP2 levels in blood monocytes from control mice and braininvading monocytes from SE mice were 76- and 7-fold higher, respectively, than control microglia (Fig. 5C). SE did not elevate EP2 levels in microglia. These findings indicate monocytes express considerably higher levels of EP2 than brain-resident microglia in both control and SE mice.

EP2 antibody validation

We next conducted a series of experiments to determine which EP2-expressing cells are actually ablated by CD11b-Cre; 180 EP2 antibodies are available from 19 suppliers. We initially used Western blots of EP2-sufficient and KO mice to evaluate four commercial antibodies for specificity. Only one tested antibody (Abcam, 167171) was found to be specific for EP2. Kidney homogenates from EP2 homozygous WT, heterozygous, and homozygous $\mathrm{KO}$ mice were probed with a monoclonal rabbit anti-EP2 antibody (Fig. 6A). A nonspecific protein band, marked as EP2 by most commercial sources, was detected migrating larger than $50 \mathrm{kDa}$ in all three homogenates. Notably, a thin band of $\sim 40 \mathrm{kDa}$ was detected in the EP2 homozygous WT and EP2 heterozygous kidney homogenates, but not in the homogenate from the EP2 homozygous KO mouse (Fig. 6A). Based on the amino acid sequence, EP2 should have a mass of $\sim 40.5 \mathrm{kDa}$.

It is not reliable to evaluate EP2 antibody specificity by immunohistochemistry with global or conditional EP2 KOs because, based on the KO strategy, an in-frame 35 amino acid C-terminal peptide with an initiating methionine could be expressed that bears the epitope of most EP2 antibodies. We thus evaluated this antibody for performance in cell lines and tissues that express high or very low EP2 mRNA levels. A C6 glioma cell line stably expressed the related prostanoid receptor DP1 with $45 \%$ amino 

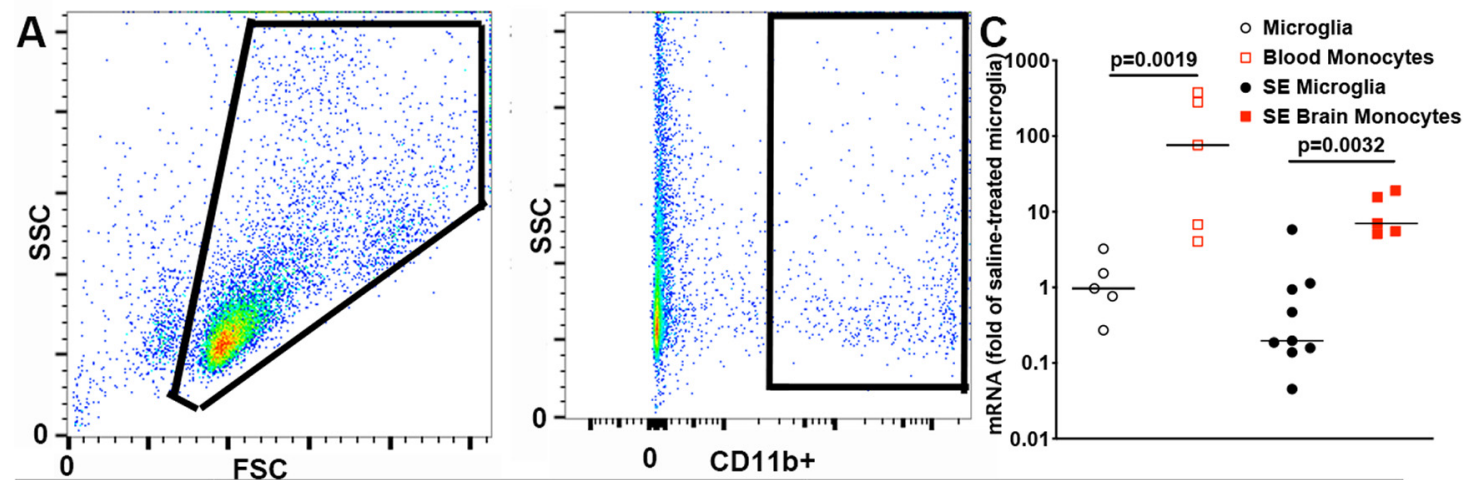

\begin{tabular}{l|c|c|c|c|c|c|}
\hline \multirow{2}{*}{$\mathbf{B}$} & \multicolumn{3}{|c|}{ FSC } & \multicolumn{3}{c|}{ McKO } \\
\cline { 2 - 7 } & $\# 1$ & $\# 2$ & $\# 3$ & $\# 4$ & $\# 5$ & $\# 6$ \\
\hline CD11b & 36.03 & 22.90 & 25.92 & 27.37 & 24.39 & 24.38 \\
\hline EP2 & 29.16 & 26.73 & 29.29 & n.d. & n.d. & n.d. \\
\hline
\end{tabular}

Figure 5. EP2 mRNA is robustly ablated in $C D 11 b^{+}$innate immune splenocyte cells from McKO mice and is more abundant in monocytes than microglia. $A$, Intact cells were first identified by side scatter (SSC) and forward scatter (FSC) (left). Single-cell suspensions of CD11 b ${ }^{+}$spleen cells from $3 \mathrm{mEP2}{ }^{+}$and 3 McK0 mice were gated on CD11b (right). $\boldsymbol{B}$, The $C_{\mathrm{t}}$ values (average of technical duplicates in each sample, which differed by a mean of 2.3\%) for (D11b and EP2 from mRNA isolated from CD11 $\mathrm{b}^{+}$splenocytes collected from $3 \mathrm{mEP2}{ }^{+}$mice (\#1-3) and $3 \mathrm{McKO}$ mice (\#4-6). The $C_{t}$ values for EP2 in McK0 splenocytes were below detection level (n.d.) in each mouse. $C$, EP2 mRNA levels for microglia and monocytes isolated as in $\boldsymbol{A}$ were normalized to the mean of microglia from saline solution-treated mice. Horizontal bar represents the median level of EP2 mRNA. Each symbol represents an individual mouse (one-way ANOVA with Sidak multiple comparison test).

acid sequence identity and $61 \%$ similarity sequence to human EP2. Whereas antibody staining revealed no positive signal in the human DP1 cell line (Fig. 6B), strong positive signal was observed in the C6 cell line overexpressing human EP2 (Fig. 6C), suggesting the rabbit monoclonal antibody has specificity for human EP2 over human DP1.

To further validate the rabbit EP2 antibody, we performed gene expression analysis and immunohistochemistry on mouse tissue sections. The mRNA levels of mouse EP2 in ovary, uterus, and spleen were each at least 100 -fold higher than that in heart (Fig. 6D). Consistent with the low level of mRNA in heart tissue, positive protein signal was not detected in heart tissue from WT mice (Fig. 6E). By contrast, robust EP2 signal was detected in ovary follicles (Fig. $6 F$ ), cells lining the lumen of the uterus (Fig. $6 G$ ), and spleen (Fig. $6 H$ ). Together, these findings indicate the rabbit monoclonal EP2 antibody has specificity for mouse EP2 in tissue sections.

\section{Blood immune cells express active CD11b-driven Cre and EP2}

A Cre reporter mouse was generated to assess cells in which Cre recombinase is active by crossing $C d 11 b$-Cre mice with the Ai9 mouse. The resultant mouse, termed $\mathrm{McKOR}$, expresses robust tdTomato fluorescence following Cre-mediated recombination. Blood smeared from McKOR mice revealed robust tdTomato fluorescent signal in CD11b-immunopositive nucleated immune cells (Fig. $7 A-D$ ). Cellular counts revealed that $15 \%$ of the total $\mathrm{DAPI}^{+}$blood cells were positive for both tdTomato and CD11b, whereas only $4 \%$ of nucleated cells were $\mathrm{CD}_{11 \mathrm{~b}^{+}}$and tdTomato ${ }^{-}$, and $2 \%$ of total cells were $\mathrm{CD} 1 \mathrm{~b}^{-}$and tdTomato ${ }^{+}$(Fig. 7E). Thus, $79 \%$ of the $\mathrm{CD} 1 \mathrm{~b}^{+}$cells in the blood $(=15 /(15+4))$ expressed active Cre, whereas only $2.5 \%$ of nominally CD $11 b^{-}$ cells expressed Cre.

Next, we examined EP2 and $\mathrm{CD}_{1} \mathrm{bb}^{+}$expression in blood cells from WT mice (Fig. $7 F-I$ ). EP2 expression was detected in $42 \%$ of nucleated $\left(\mathrm{DAPI}^{+}\right.$) blood cells, and $73 \%$ of the $\mathrm{CD} 11 \mathrm{~b}^{+}$ cells also expressed EP2 (Fig. 7J). Together, these findings indicate active Cre is present in the overwhelming majority of CD11b-expressing blood immune cells, and most CD11b ${ }^{+}$cells express EP2.

EP2 is expressed by neural cells, but only a subset of cells expresses active Cre recombinase

Immunohistological analysis of brain tissue sections from WT mice indicated that low-level EP2 expression was observed broadly in $\mathrm{CD}_{11 \mathrm{~b}^{+}}$microglia (Fig. $8 A-C$ ) and in some CD $31^{+}$ endothelia (Fig. 8G-I). EP2 immunoreactive neurons were also encountered throughout the cortex, hippocampus, and subcortical regions. Interestingly, despite clear CD11b expression in microglia, the McKOR mouse revealed that only a very small subset of microglia expresses active Cre (Fig. $8 D-F$ ). Indeed, most brain tissue sections had no tdTomato $^{+}$microglia, but occasionally a rare cluster of three or four tdTomato ${ }^{+}$microglia was observed (e.g., Fig. 8D). Similarly, only a subset of CD31 ${ }^{+}$ endothelia expressed tdTomato, indicating active Cre recombinase (Fig. $8 J-L$ ). Together, we conclude EP2 is eliminated from a very small minority of brain microglia and a subset of brain endothelial cells in the $\mathrm{McKO}$ mouse, in contrast to robust ablation of EP2 in blood immune cells (Figs. 5, 7).

Global EP2 antagonism prevents monocyte brain invasion Monocytes infiltrate the brain between 1 and $3 \mathrm{~d}$ after kainateinduced SE, and prevention of monocyte infiltration in the kainate SE model in the CCR2 KO mouse has the same beneficial effects as pharmacologic block of EP2 in the pilocarpine SE mouse model (Varvel et al., 2016). For this reason, we determined whether EP2 activation is required for monocyte brain infiltration after SE. We subjected heterozygous $C c r 2^{+/ r p p}$ mice to the brain-permeable EP2 antagonist, TG6-10-1, which has previously been shown to reduce brain inflammation, provide neuroprotection, and enhance weight regain after SE (Jiang et al., 2013; Rojas et al., 2015). In heterozygous $C c r 2^{+/ r f p}$ mice, blood-borne monocytes express RFP, but brain-resident microglia do not express CCR2 or RFP (Saederup et al., 2010; Mizutani et al., 

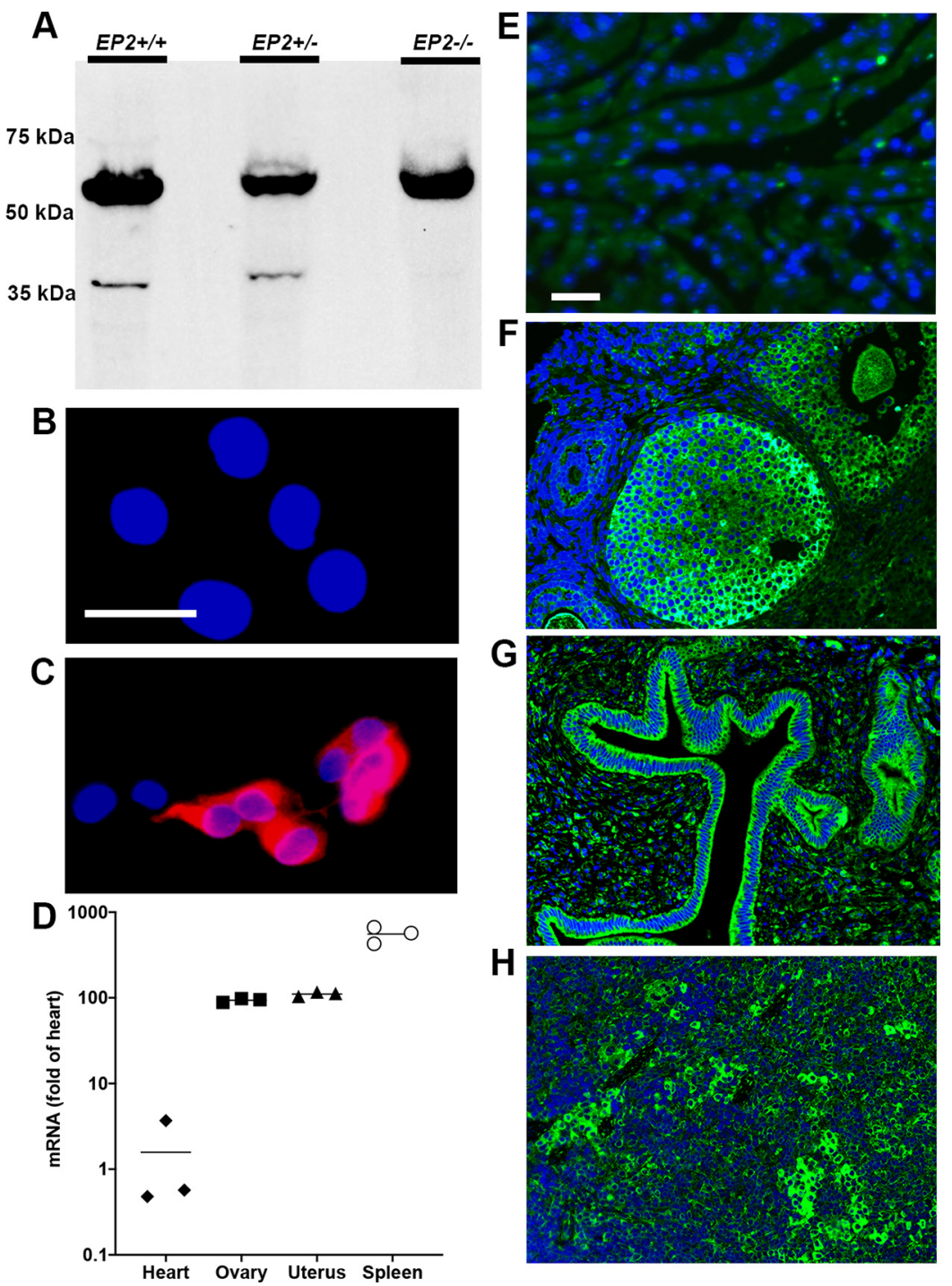

$\mathrm{H}$

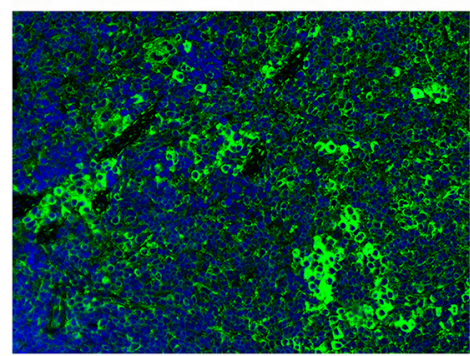

Figure 6. Validation of rabbit monoclonal anti-EP2 antibody. A, EP2 protein in kidney homogenates of EP2 homozygous WT $\left(E P 2^{+/+}\right)$, heterozygous $\left(E P 2^{+/-}\right)$, and global KO $\left(E P 2^{-l-}\right)$. A nonspecific band migrating larger than $50 \mathrm{kDa}$ in all three homogenates was detected by the anti-EP2 antibody (Abcam, ab167171). A band migrating at $\sim 40 \mathrm{kDa}$ was detected in the kidney homogenate from $\mathrm{EP}^{+/+}$and $E P 2^{+/-}$mice but not kidney homogenate from $E P 2^{-1-}$ mice. EP2 immunoreactivity is not observed in 66 cells expressing human DP1 (B), but EP2 reactivity is seen in C6 cells expressing human EP2 (red) (C). Cells are stained with DAPI (blue). Scale bars: $\boldsymbol{B}, \boldsymbol{C}, 25 \mu \mathrm{m}$. D, EP2 mRNA levels for four organs normalized to heart are plotted. Each symbol represents an individual mouse. Line indicates the mean. The ovary, uterus, and spleen were each significantly elevated over heart (ANOVA, $F_{(3,8)}=$ $65.89, p<0.0001$ ) after Dunnett's with $p<0.0001$ for each comparison to heart. Immunohistochemistry on tissue sections from heart $(\boldsymbol{E})$, ovary $(\boldsymbol{F})$, uterus $(\boldsymbol{G})$, and spleen $(\boldsymbol{H})$. Scale bars: $\boldsymbol{E}-\boldsymbol{H}, 50 \mu \mathrm{m}$. Sections are countered with DAPI (blue).

2011). Moreover CCR2-RFP-positive monocytes are rarely observed in control mouse brain tissue (Varvel et al., 2012, 2016), confirming that monocyte infiltration into the healthy brain is rare (Prinz et al., 2011). Thus, $C c r 2^{+/ r f p}$ mice are a useful model to distinguish brain-invading monocytes from brain-resident microglia when both cells are in the brain.

Anti-RFP staining and examination of hippocampal tissue 3 $\mathrm{d}$ after kainate-induced SE revealed brain invasion of CCR2RFP-expressing monocytes (Fig. 9A, left). Interestingly, the EP2 antagonist TG6-10-1 substantially reduced the number of $\mathrm{Ccr} 2^{+/ r f p}$ brain-invading monocytes (Fig. $9 A$, right). In these experiments, mice were injected with vehicle or TG6-10-1 (5 mg/kg i.p.) 4, 21, and $30 \mathrm{~h}$ after SE onset, and killed $3 \mathrm{~d}$ after SE. Stereological analysis of CCR2-RFP-expressing monocytes showed $\sim 86,000$ monocytes in the hippocampus of vehicle-injected mice, whereas fewer than 13,000 monocytes were encountered in SE mice subjected to EP2 antagonism with TG6-10-1 (Fig. 9B).

We further evaluated the effects of TG6-10-1 in the mouse kainate SE model for comparison with the pilocarpine model. Kainate SE mice subject to the EP2 antagonist began to regain weight $24 \mathrm{~h}$ after SE, whereas weight regain was delayed in vehicle-treated mice, beginning $>48$ $\mathrm{h}$ after SE. There was a statistically significant difference in weight change from day 1 to day 3 between treatment groups (Fig. 9C; $p=0.001$ ). Hippocampal levels of inflammatory mediators CCL2, IL- $1 \beta$, IL-6, and TNF $\alpha$ were each depressed by $>50 \%$ in TG6-10-1-treated SE mice compared with vehicle-treated SE mice (Fig. 9D). In these experiments, the levels of serum albumin were much higher in cortical homogenates obtained from vehicle-treated mice after SE compared with SE mice administered TG6-10-1 (Fig. 9E). Finally, hippocampal tissue was examined for neuronal damage. The wellrecognized kainate-induced neuronal injury pattern was apparent (Buckmaster and Dudek, 1997; Rojas et al., 2014) as extensive damage to the CA3 subfield of the hippocampus was observed (Fig. 9F). The number of $\mathrm{FJB}^{+}$pyramidal neurons was reduced in both CA1 and CA3 subfields following treatment with TG6-10-1. On average, 222 dying CA3 neurons per section were identified in vehicle-treated mice, whereas 105 stained neurons were counted in mice subjected to the EP2 antagonist after SE (Fig. 9G; $p=0.04$ ). Cumulatively, these results confirm those of Jiang et al. (2019) and extend results from the pilocarpine model to the kainate model of SE, showing that systemic EP2 antagonism after pilocarpine- or diisopropyl fluorophosphateinduced SE results in a broad range of beneficial effects (Jiang et al., 2013; Rojas et al., 2015, 2016). Importantly, these results indicate that pharmacologic inhibition of EP2 prevents pathogenic monocyte recruitment to the SE brain.

\section{Discussion}

In the pilocarpine SE model, the beneficial effects of Cox-2 ablation limited to principal forebrain neurons (Serrano et al., 2011; Levin et al., 2012) are replicated by global pharmacologic block of the EP2 receptor for PGE2 ( Jiang et al., 2013, 2015, 2019; Rojas et al., 2015, 2016), which implies that EP2 activation mediates much of the harmful effects of the Cox- 2 inflammatory cascade after SE. Our studies extend this finding to the kainate SE model and were designed to identify the effects of pharmacologic EP2 antagonism that can be attributed to EP2 receptor expression in innate immune myeloid cells, mainly microglia and monocytes. Importantly, $\mathrm{mEP}^{+}$and $\mathrm{McKO}$ mice display similar seizure severity scores and latency to pilocarpine SE, so meaningful interpretation of the consequences of the selective ablation of EP2 in myeloid cells on SE-induced phenotypes is possible. 


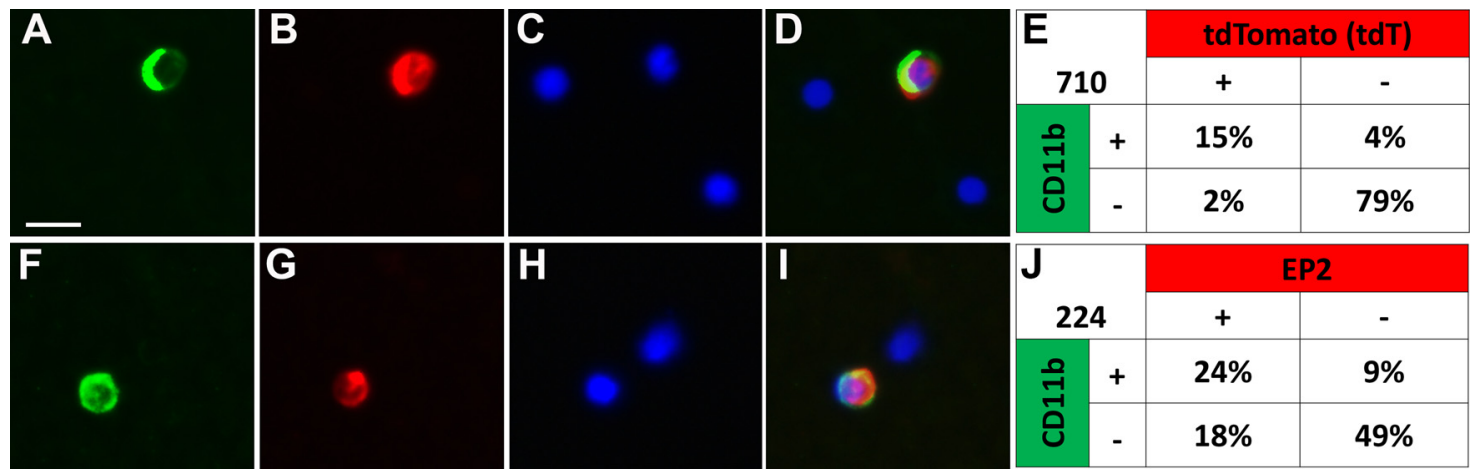

Figure 7. Immunophenotyping of blood cells. $\boldsymbol{A}-\boldsymbol{D}$, Blood smears from McKOR mice stained for CD11b ( $\boldsymbol{A}$, green) and DAPI ( $\boldsymbol{C}$, blue) and expressing tdTomato ( $\boldsymbol{B}$, red) with merged images (D). $\boldsymbol{E}$, A total of $710 \mathrm{DAPI}^{+}$cells were scored for the presence or absence of CD11b and tdTomato. The percentage of total scored cells exhibiting the four possible phenotypes is shown. $\boldsymbol{F}-\boldsymbol{I}$, Blood smears from WT mice stained for CD11b $\left(\boldsymbol{F}\right.$, green), EP2 ( $\boldsymbol{G}$, red), and DAPI $\left(\boldsymbol{H}\right.$, blue) with merged images $(\boldsymbol{I})$. J, A total of 224 DAPI $^{+}$cells were scored for the presence or absence of CD11b and EP2. The percentage of total scored cells exhibiting the four possible phenotypes is shown. Scale bars: $A-D, F-I, 5 \mu \mathrm{m}$.

Here, we show that ablation of EP2 in microglia and monocytes, but primarily monocytes, alleviates many of the deleterious consequences of pilocarpine SE, including prevention of IL-6 induction in hippocampal tissue and SE-induced opening of the $\mathrm{BBB}$. Moreover, $\mathrm{McKO}$ mice display enhanced weight regain and improved Irwin scores in the days following SE compared with their EP2-sufficient littermates, indicating that myeloid EP2 activation contributes to the early behavioral deficits following SE. Most unexpectedly, the McKOR mouse revealed that active CD11b-driven Cre recombinase included $\mathrm{CD} 31^{+} \mathrm{EP} 2$-expressing endothelial cells within the brain. Thus, limited EP2 ablation from brain endothelia might also contribute to alleviation of the adverse effects of SE. In contrast to pharmacologic EP2 antagonism after pilocarpine SE (Jiang et al., 2013; Rojas et al., 2015), myeloid cell EP2 ablation did not result in neuroprotection in the hippocampus nor in blunted induction of IL- $1 \beta$ or TNF $\alpha$. Our previous studies have suggested that the source of PGE2 to activate EP2 is likely principal forebrain neurons (Serrano et al., 2011), which together with these results reveals a form of neuron-microglia or neuron-monocyte paracrine communication.

Disruption of the BBB is a common event in numerous neurologic disorders and can contribute to brain injury (Sweeney et al., 2019). Leakage of serum albumin into the brain after SE could promote the development of epilepsy because direct administration of albumin into the brain can result in the appearance of an epileptic focus that evolves into spontaneous seizures (Ivens et al., 2007). Additionally, deterioration of the BBB has been documented in epileptic humans by measuring the extravasation of serum albumin into the brain parenchyma (van Vliet et al., 2007). In rodents, the integrity of the $\mathrm{BBB}$ is compromised within hours of pilocarpine SE and persists for weeks after kainate SE (van Vliet et al., 2014; Bankstahl et al., 2018).

Beneficial outcomes have been attributed to global EP2 ablation in a mouse model of amyotrophic lateral sclerosis (Liang et al., 2008). Myeloid cell ablation of EP2 suppressed inflammation, enhanced amyloid clearance, and prevented
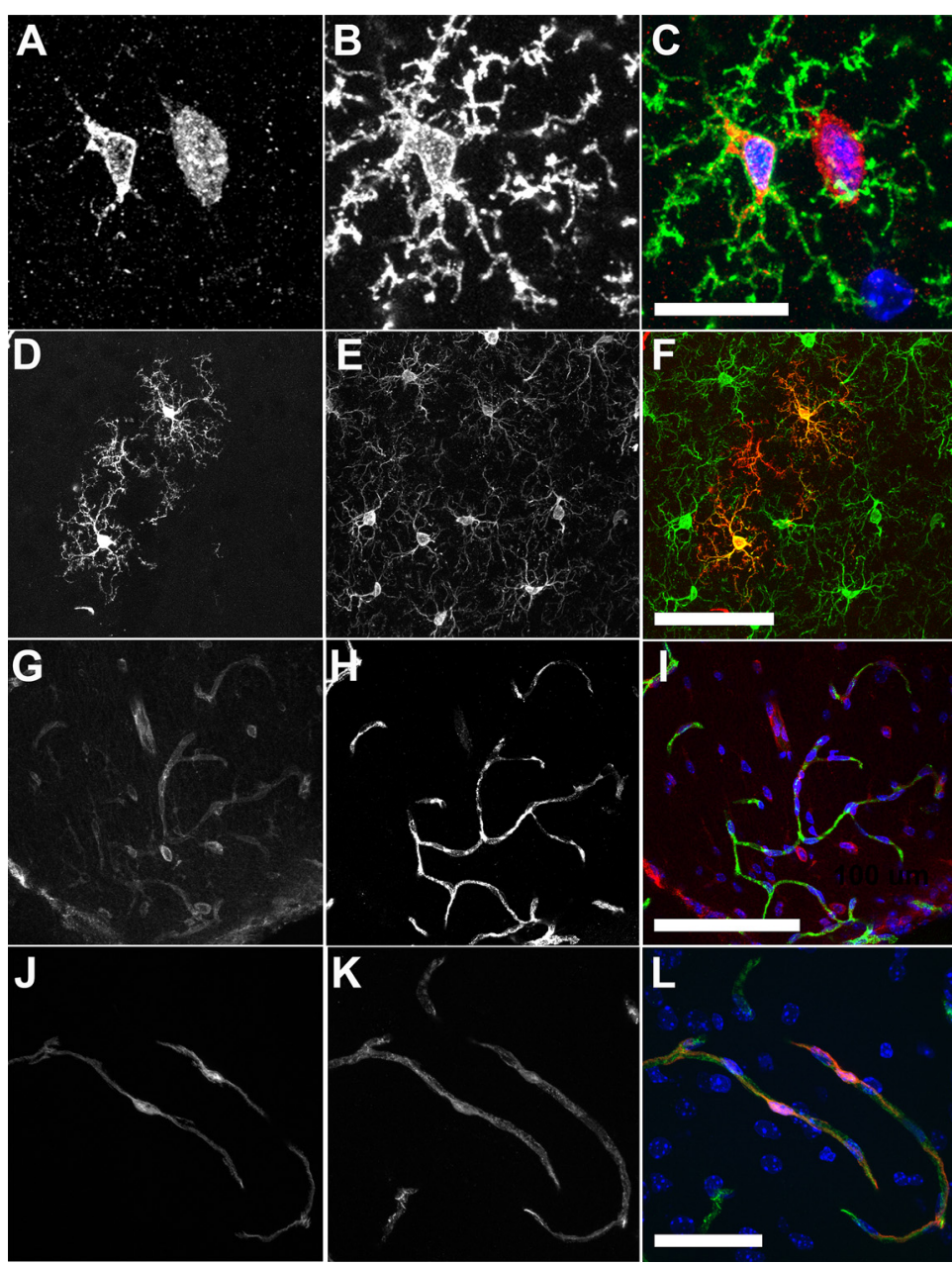

Figure 8. Microglia and endothelia cells express EP2, but only a subset express active Cre recombinase. EP2 $(\boldsymbol{A})$ is expressed by $\mathrm{CD}_{11 \mathrm{~b}^{+}}(\boldsymbol{B})$ microglia in WT mice. A small subset of usually clustered $\mathrm{lba} 1^{+}(\boldsymbol{E})$ microglia express the tdTomato reporter $(\boldsymbol{D})$ driven by CD11b-Cre in McKOR mice demonstrating active Cre recombinase. EP2 (G) is expressed by some $\mathrm{CD}^{+} 1^{+}(\boldsymbol{H})$ endothelial cells in WT mice. A subset of $\mathrm{CD}^{+} 1^{+}(\boldsymbol{K})$ endothelial cells express the tdTomato reporter (I) in McKOR mice indicating active (re, possibly because of ectopic expression from the $C d 11 b$-Cre. $C, F, I, J$, Merged images. Nuclei are counterstained with DAPI (blue). Scale bars: A-C, $25 \mu \mathrm{m} ; \mathrm{J}-\mathrm{L}, 50 \mu \mathrm{m} ; \mathrm{D}-\mathrm{I}, 100 \mu \mathrm{m}$.

synaptic injury and memory deficits in an Alzheimer's disease model (Johansson et al., 2013, 2015). Moreover, multiple beneficial effects are encountered after administration of a brain-permeable EP2 antagonist starting 2-4 h after diisopropyl fluorophosphate- 
A

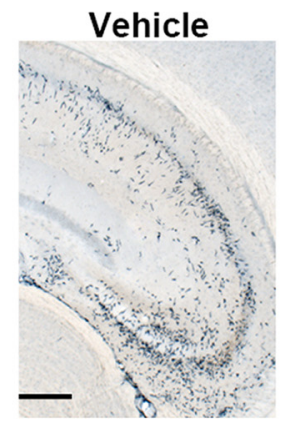

C
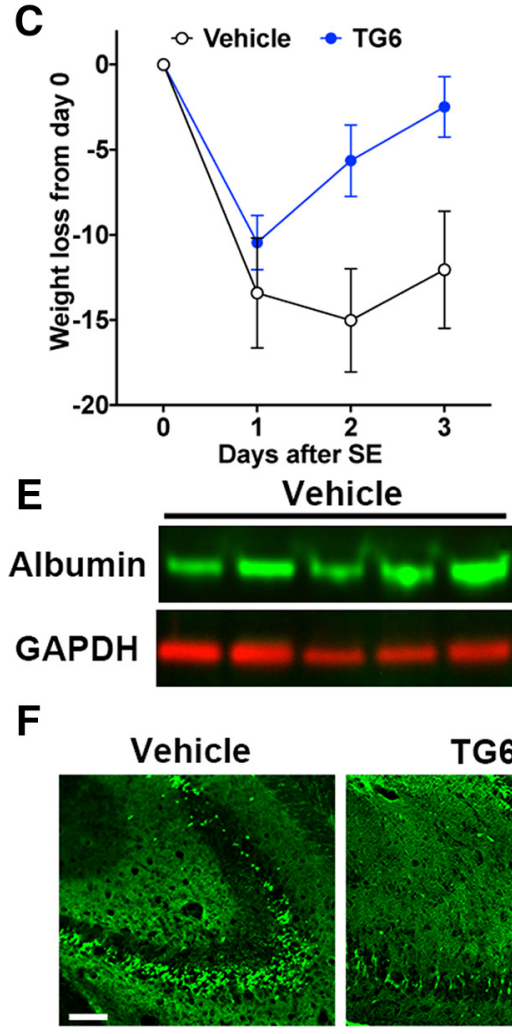

B

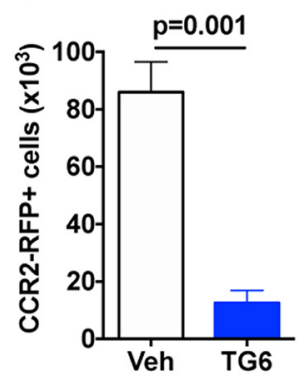

D

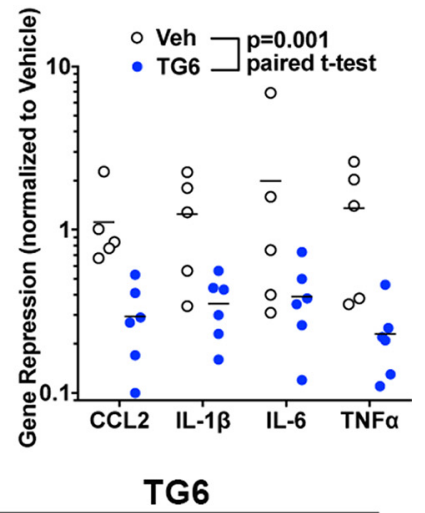

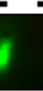
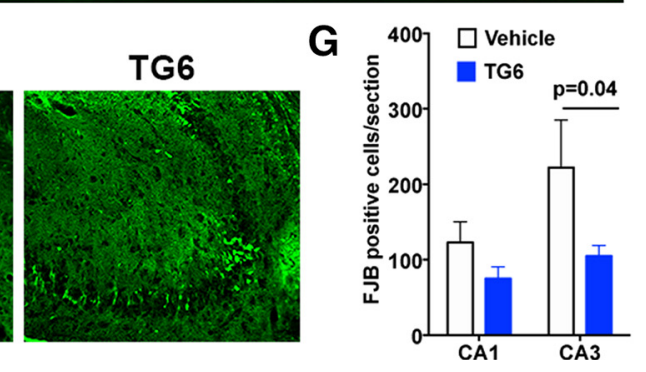

Figure 9. EP2 antagonism relieves the deleterious consequences of kainate-induced SE. $A, C \mathrm{Cr} 2^{+/ / f p}$ mice $(n=5)$ subject to kainate and vehicle treatment showed hippocampal infiltration of CCR2-RFP ${ }^{+}$monocytes $3 \mathrm{~d}$ after SE, whereas SE C $\mathrm{Cr}^{+/ 1 f p}$ mice subject to TG6-10-1 (TG6) $(n=6)$ displayed greatly reduced numbers of CCR2-RFP ${ }^{+}$ monocytes in the hippocampus. $\boldsymbol{B}$, Stereological analysis revealed $\sim 86,000$ monocytes in vehicle-treated mice $3 \mathrm{~d}$ after $S E$ and $\sim 12,500$ monocytes in mice treated with TG6-10-1 ( $t$ test, $p=0.001$ ). C, TG6-10-1-treated mice (blue circles) regained lost weight faster than vehicle-treated mice (open circles) (two-way ANOVA, the effect of treatment, $\left.F_{(1,27)}=12.67, p=0.0014\right)$. $\boldsymbol{D}$, Horizontal line indicates mean fold induction of the inflammatory mediators in hippocampus and is plotted for vehicle-treated and TG6-10-1-treated $3 \mathrm{~d}$ after SE. Each symbol represents an individual mouse, with induction referenced to the mean of the vehicle-treated group (paired $t$ test, $p=0.001$ ). $\boldsymbol{E}_{\text {, }}$ Albumin protein levels in cortical homogenates of vehicle-treated and TG6-10-1-treated mice were measured by Western blot with GAPDH as loading control. F, FJB staining in hippocampal tissue sections $3 \mathrm{~d}$ after SE shows more injured neurons in CA3 subfield of TG6-10-1-treated mice compared with vehicle-treated mice. G, Plot of the number of $\mathrm{FJB}^{+}$cells in hippocampal cell layers. Error bars indicate mean $\pm \mathrm{SEM}$ of each group. Significant differences were found by one-way ANOVA $\left(F_{(3,18)}=3.593, p=0.03\right)$ followed by Sidak multiple comparison test $(p=0.04)$.

or pilocarpine-induced SE onset, namely, a reduction in delayed mortality, blunted neuroinflammation, prevention of $\mathrm{BBB}$ opening, neuroprotection, accelerated weight regain, and cognitive improvement (Jiang et al., 2013, 2015; Rojas et al., 2015, 2016). In contrast, global EP2 genetic ablation increased infarct size in a model of focal ischemia (McCullough et al., 2004), and intraventricular delivery of an EP2 agonist immediately after pilocarpine-induced SE in a rat model is neuroprotective (Serrano et al., 2011). These seemingly contrasting observations might be attributed to divergent consequences of EP2 activation after neurologic insult, wherein EP2 activation is neuroprotective early and neurotoxic later, or they might be because of opposing effects of EP2 antagonism on different cell types, which motivated this study.

We found active CD11b-driven Cre recombinase in very few brain microglia, but in a subset of brain endothelia. This unexpected finding prompted us to look more carefully at CD11bdriven Cre expression in our mice. We found that $79 \%$ of $\mathrm{CD}_{11 \mathrm{~b}^{+}}$blood cells express active Cre, and EP2 is observed in $72 \%$ of CD11bexpressing cells. Thus, EP2 ablation in microglia is unlikely to account for much, if any, of the beneficial post-SE phenotypes observed in the McKO mouse. Instead, we attribute the beneficial impact of conditional EP2 ablation in the McKO mice largely to preventing EP2 activation in blood circulating $\mathrm{CD} 1 \mathrm{~b}^{+}$cells (monocytes and neutrophils) and possibly brain endothelia. Indeed, EP2 mRNA was virtually abolished in CD11b-expressing splenocytes isolated from $\mathrm{McKO}$ mice. Previous studies have identified the spleen as a source of $\mathrm{CD}_{11 b^{+}} \mathrm{Ly}_{6} \mathrm{C}^{\text {high }}$ monocytes recruited to the heart after ischemic myocardial injury (Swirski et al., 2009) and brain in response to repeated social defeat (Wohleb et al., 2014). Thus, it is conceivable that the spleen acts as a reservoir for brain-infiltrating monocytes before SE. However, additional experiments will be needed to demonstrate this.

Microglial EP2 has been implicated in paracrine neurotoxicity following lipopolysaccharide-induced inflammation in vitro (Shie et al., 2005). However, ablation of EP2 from myeloid cells did not result in neuronal protection after pilocarpine SE. These conflicting findings might be explained by the observation that EP2 is expressed highly by microglia in vitro (Quan et al., 2013) but only at low levels by most brainresident microglia (Fig. 5). Our current and previous studies have demonstrated that systemic EP2 antagonism, delayed for 2-4 h after pilocarpine SE, is neuroprotective (Jiang et al., 2013; Rojas et al., 2015). We have extended this finding to the kainate SE model here (see also Jiang et al., 2019), eliminating the chance that the neuroprotective effect of EP2 antagonism after SE is model-specific. It currently remains unclear on which cell type EP2 antagonism elicits neuroprotective effects, but the absence of neuronal protection in the $\mathrm{McKO}$ mice suggests that myeloid EP2 activation is not responsible for neuronal damage after pilocarpine SE.

A novel finding in the current study is that pharmacologic EP2 antagonism after kainate SE prevented circulating peripheral monocytes from infiltrating hippocampal tissue. We recently identified brain-invading CCR ${ }^{+}$Ly $6 \mathrm{C}^{\text {high }}$ inflammatory monocytes as one driver of inflammation, neuronal damage, BBB dysfunction, and weight loss after pilocarpine-induced SE (Varvel et al., 2016). One explanation is that EP2 antagonism prevents 
monocyte recruitment by quenching early brain inflammation, namely, the production of chemokines. Indeed, the induction of hippocampal Ccl2, a ligand for chemokine receptor, is suppressed after EP2 antagonism after SE in kainate and pilocarpine SE models (Jiang et al., 2013; Rojas et al., 2015). Another possibility is that inhibiting EP2 signaling directly on monocytes might block their recruitment to the brain. The current observation that monocyte brain recruitment and hippocampal inflammation are both inhibited by systemic EP2 antagonism raises the intriguing hypothesis that the benefits of EP2 antagonism might be largely attributed to blocking monocyte recruitment to the brain after SE.

Infiltration of monocytes into the brain has been reported after Theiler's murine encephalomyelitis virus injection, which causes brief behavioral seizures in mice (Howe et al., 2012; Kaufer et al., 2018). Interestingly, mice infected with Theiler's murine encephalomyelitis virus have fewer behavioral seizures (Racine Stage 3-5) in the $21 \mathrm{~d}$ after virus infection when braininvading monocytes were deficient in IL-6 (Libbey et al., 2011), highlighting an important role for both monocyte brain invasion and IL-6 in seizure activity in this disease model. In the current study, IL-6 induction was selectively abolished in McKO mice, and EP2 antagonism blocked monocyte brain recruitment. These findings prompt us to hypothesize that targeting EP2 signaling, IL-6 signaling, monocyte brain infiltration, or a combination of the three, might have antiepileptogenic effects, which is a subject for future studies.

Before the present studies, we had assumed that EP2 antagonism was predominantly targeting inflammatory pathways originating within the CNS. The discovery that EP2 elimination in peripheral immune cells, and not microglia, attenuates multiple SE-induced effects supports a prominent role for peripheral immune cells in the immediate consequences of SE. Additionally, the finding that systemic block of EP2 after SE prevents inflammatory monocyte infiltration into the brain raises the possibility that the beneficial effects of pharmacologic EP2 inhibition can be partly or largely explained by reduced monocyte infiltration. Together, these findings suggest that EP2 signaling in blood circulating innate immune myeloid cells and brain endothelial cells drive behavioral deficits, inflammation, and opening of the BBB after SE.

\section{References}

Bankstahl M, Breuer H, Leiter I, Markel M, Bascunana P, Michalski D, Bengel FM, Loscher W, Meier M, Bankstahl JP, Hartig W (2018) Bloodbrain barrier leakage during early epileptogenesis is associated with rapid remodeling of the neurovascular unit. eNeuro 5:ENEURO.0123-18.2018.

Boillee S, Yamanaka K, Lobsiger CS, Copeland NG, Jenkins NA, Kassiotis G, Kollias G, Cleveland DW (2006) Onset and progression in inherited ALS determined by motor neurons and microglia. Science 312:1389-1392.

Borges K, Gearing M, McDermott DL, Smith AB, Almonte AG, Wainer BH, Dingledine R (2003) Neuronal and glial pathological changes during epileptogenesis in the mouse pilocarpine model. Exp Neurol 182:21-34.

Broekaart DW, Anink JJ, Baayen JC, Idema S, de Vries HE, Aronica E, Gorter JA, van Vliet EA (2018) Activation of the innate immune system is evident throughout epileptogenesis and is associated with blood-brain barrier dysfunction and seizure progression. Epilepsia 59:1931-1944.

Buckmaster PS, Dudek FE (1997) Neuron loss, granule cell axon reorganization, and functional changes in the dentate gyrus of epileptic kainatetreated rats. J Comp Neurol 385:385-404.

Cardona AE, Huang D, Sasse ME, Ransohoff RM (2006) Isolation of murine microglial cells for RNA analysis or flow cytometry. Nat Protoc 1:19471951.

Charo IF, Ransohoff RM (2006) The many roles of chemokines and chemokine receptors in inflammation. N Engl J Med 354:610-621.
Hizaki H, Segi E, Sugimoto Y, Hirose M, Saji T, Ushikubi F, Matsuoka T, Noda Y, Tanaka T, Yoshida N, Narumiya S, Ichikawa A (1999) Abortive expansion of the cumulus and impaired fertility in mice lacking the prostaglandin E receptor subtype EP(2). Proc Natl Acad Sci USA 96:1050110506.

Ho J, Tumkaya T, Aryal S, Choi H, Claridge-Chang A (2019) Moving beyond P values: data analysis with estimation graphics. Nat Methods 16:565566.

Howe CL, Lafrance-Corey RG, Sundsbak RS, Sauer BM, Lafrance SJ, Buenz EJ, Schmalstieg WF (2012) Hippocampal protection in mice with an attenuated inflammatory monocyte response to acute. Sci Rep 2:545.

Irwin S (1968) Comprehensive observational assessment: Ia. A systematic, quantitative procedure for assessing the behavioral and physiologic state of the mouse. Psychopharmacologia 13:222-257.

Ivens S, Kaufer D, Flores LP, Bechmann I, Zumsteg D, Tomkins O, Seiffert E, Heinemann U, Friedman A (2007) TGF-beta receptor-mediated albumin uptake into astrocytes is involved in neocortical epileptogenesis. Brain 130:535-547.

Jiang J, Quan Y, Ganesh T, Pouliot WA, Dudek FE, Dingledine R (2013) Inhibition of the prostaglandin receptor EP2 following status epilepticus reduces delayed mortality and brain inflammation. Proc Natl Acad Sci USA 110:3591-3596.

Jiang J, Yang MS, Quan Y, Gueorguieva P, Ganesh T, Dingledine R (2015) Therapeutic window for cyclooxygenase-2 related anti-inflammatory therapy after status epilepticus. Neurobiol Dis 76:126-136.

Jiang J, Yu Y, Kinjo ER, Du Y, Nguyen HP, Dingledine R (2019) Suppressing pro-inflammatory prostaglandin signaling attenuates excitotoxicity-associated neuronal inflammation and injury. Neuropharmacology 149:149160.

Johansson JU, Pradhan LA, Lokteva NS, Woodling N, Ko HD, Brown Q, Wang C, Loh E, Cekanaviciute M, Buckwalter AB, Manning-Bog AB, Andreasson KI (2013) Suppression of inflammation with conditional deletion of the prostaglandin E2 EP2 receptor in macrophages and brain microglia. J Neurosci 33:16016-16032.

Johansson JU, Woodling NS, Wang Q, Panchal M, Liang X, Trueba-Saiz A, Brown HD, Mhatre SD, Loui T, Andreasson KI (2015) Prostaglandin signaling suppresses beneficial microglial function in Alzheimer's disease models. J Clin Invest 125:350-364.

Kaufer C, Chhatbar C, Broer S, Waltl I, Ghita L, Gerhauser I, Kalinke U, Loscher W (2018) Chemokine receptors CCR2 and CX3CR1 regulate viral encephalitis-induced hippocampal damage but not seizures. Proc Natl Acad Sci USA 115:E8929-E8938.

Kennedy CR, Zhang Y, Brandon S, Guan Y, Coffee K, Funk CD, Magnuson MA, Oates JA, Breyer MD, Breyer RM (1999) Salt-sensitive hypertension and reduced fertility in mice lacking the prostaglandin EP2 receptor. Nat Med 5:217-220.

Levin JR, Serrano G, Dingledine R (2012) Reduction in delayed mortality and subtle improvement in retrograde memory performance in pilocarpinetreated mice with conditional neuronal deletion of cyclooxygenase-2 gene. Epilepsia 53:1411-1120.

Liang X, Wang Q, Shi J, Lokteva L, Breyer RM, Montine TJ, Andreasson K (2008) The prostaglandin E2 EP2 receptor accelerates disease progression and inflammation in a model of amyotrophic lateral sclerosis. Ann Neurol 64:304-314.

Libbey JE, Kennett NJ, Wilcox KS, White HS, Fujinami RS (2011) Interleukin-6, produced by resident cells of the central nervous system and infiltrating cells, contributes to the development of seizures following viral infection. J Virol 85:6913-6922.

Long JM, Kalehua AN, Muth NJ, Calhoun ME, Jucker M, Hengemihle JM, Ingram DK, Mouton PR (1998) Stereological analysis of astrocyte and microglia in aging mouse hippocampus. Neurobiol Aging 19:497-503.

Madisen L, Zwingman TA, Sunkin SM, Oh SW, Zariwala HA, Gu H, Ng LL, Palmiter RD, Hawrylycz MJ, Jones AR, Lein ES, Zeng H (2010) A robust and high-throughput Cre reporting and characterization system for the whole mouse brain. Nat Neurosci 13:133-140.

McCullough L, Wu L, Haughey N, Liang X, Hand T, Wang Q, Breyer RM, Andreasson K (2004) Neuroprotective function of the PGE2 EP2 receptor in cerebral ischemia. J Neurosci 24:257-268.

Mizutani M, Pino PA, Saederup N, Charo IF, Ransohoff RM, Cardona AE (2011) The fractalkine receptor but not CCR2 is present on microglia from embryonic development throughout adulthood. J Immunol 188:2936. 
Prinz M, Priller J (2010) Tickets to the brain: role of CCR2 and CX3CR1 in myeloid cell entry in the CNS. J Neuroimmunol 224:80-84.

Prinz M, Priller J, Sisodia SS, Ransohoff RM (2011) Heterogeneity of CNS myeloid cells and their roles in neurodegeneration. Nat Neurosci 14:1227-1235

Quan Y, Jiang J, Dingledine R (2013) EP2 receptor signaling pathways regulate classical activation of microglia. J Biol Chem 288:9293-9302.

Rojas A, Gueorguieva P, Lelutiu N, Quan Y, Shaw R, Dingledine R (2014) The prostaglandin EP1 receptor potentiates kainate receptor activation via a protein kinase $\mathrm{C}$ pathway and exacerbates status epilepticus. Neurobiol Dis 70:74-89.

Rojas A, Ganesh T, Lelutiu N, Gueorguieva P, Dingledine R (2015) Inhibition of the prostaglandin EP2 receptor is neuroprotective and accelerates functional recovery in a rat model of organophosphorus induced status epilepticus. Neuropharmacology 93:15-27.

Rojas A, Ganesh T, Manji Z, O’Neill T, Dingledine R (2016) Inhibition of the prostaglandin E2 receptor EP2 prevents status epilepticus-induced deficits in the novel object recognition task in rats. Neuropharmacology 110:419-430.

Saederup N, Cardona AE, Croft K, Mizutani M, Cotleur AC, Tsou CL, Ransohoff RM, Charo IF (2010) Selective chemokine receptor usage by central nervous system myeloid cells in CCR2-red fluorescent protein knock-in mice. PLoS One 5:e13693.

Sakuma H, Tanuma N, Kuki I, Takahashi Y, Shiomi M, Hayashi M (2015) Intrathecal overproduction of proinflammatory cytokines and chemokines in febrile infection-related refractory status epilepticus. J Neurol Neurosurg Psychiatry 86:820-822.

Serrano GE, Lelutiu N, Rojas A, Cochi S, Shaw R, Makinson CD, Wang D, FitzGerald GA, Dingledine R (2011) Ablation of cyclooxygenase-2 in forebrain neurons is neuroprotective and dampens brain inflammation after status epilepticus. J Neurosci 31:14850-14860.

Shie FS, Montine KS, Breyer RM, Montine TJ (2005) Microglial EP2 is critical to neurotoxicity from activated cerebral innate immunity. Glia 52:70-77.

Sweeney MD, Zhao Z, Montagne A, Nelson AR, Zlokovic BV (2019) Bloodbrain barrier: from physiology to disease and back. Physiol Rev 99: 21-78.
Swirski FK, Nahrendorf M, Etzrodt M, Wildgruber M, Cortez-Retamozo V, Panizzi P, Figueiredo JL, Kohler RH, Chudnovskiy A, Waterman P, Aikawa E, Mempel TR, Libby P, Weissleder R, Pittet MJ (2009) Identification of splenic reservoir monocytes and their deployment to inflammatory sites. Science 325:612-616.

Tian DS, Peng J, Murugan M, Feng LJ, Liu JL, Eyo UB, Zhou LJ, Mogilevsky R, Wang W, Wu LJ (2017) Chemokine CCL2-CCR2 signaling induces neuronal cell death via STAT3 activation and IL-1beta production after status epilepticus. J Neurosci 37:7878-7892.

van Vliet EA, da Costa Araujo S, Redeker S, van Schaik R, Aronica E, Gorter JA (2007) Blood-brain barrier leakage may lead to progression of temporal lobe epilepsy. Brain 130:521-534.

van Vliet EA, Otte WM, Gorter JA, Dijkhuizen RM, Wadman WJ (2014) Longitudinal assessment of blood-brain barrier leakage during epileptogenesis in rats: a quantitative MRI study. Neurobiol Dis 63:74-84.

Varvel NH, Grathwohl SA, Baumann F, Liebig C, Bosch A, Brawek B, Thal DR, Charo IF, Heppner FL, Aguzzi A, Garaschuk O, Ransohoff RM, Jucker M (2012) Microglial repopulation model reveals a robust homeostatic process for replacing CNS myeloid cells. Proc Natl Acad Sci USA 109:18150-18155.

Varvel NH, Jiang J, Dingledine R (2015) Candidate drug targets for prevention or modification of epilepsy. Annu Rev Pharmacol Toxicol 55:229_ 247.

Varvel NH, Neher JJ, Bosch A, Wang W, Ransohoff RM, Miller RJ, Dingledine R (2016) Infiltrating monocytes promote brain inflammation and exacerbate neuronal damage after status epilepticus. Proc Natl Acad Sci USA 113:E5665-E5674.

Vezzani A, Dingledine R, Rossetti AO (2015) Immunity and inflammation in status epilepticus and its sequelae: possibilities for therapeutic application. Expert Rev Neurother 15:1081-1092.

Wohleb ES, McKim DT, Shea ND, Powell AJ, Tarr JF, Sheridan JP, Godbout (2014) Re-establishment of anxiety in stress-sensitized mice is caused by monocyte trafficking from the spleen to the brain. Biol Psychiatry 75:970-981. 